\title{
BUSINESS CYCLE SYNCHRONISATION \\ IN EAST ASIA
}

by Fabio Moneta and Rasmus Rüffer 
EUROPEAN CENTRAL BANK

\title{
WORKING PAPER SERIES
}

NO 67 I / AUGUST 2006

\author{
BUSINESS CYCLE \\ SYNCHRONISATION \\ IN EAST ASIA'
}

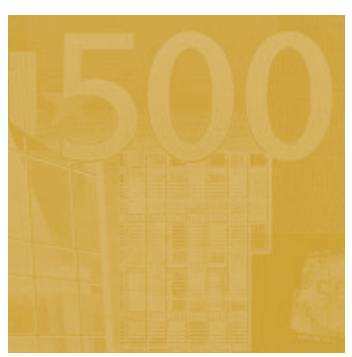

by Fabio Moneta ${ }^{2}$

and Rasmus Rüffer ${ }^{3}$

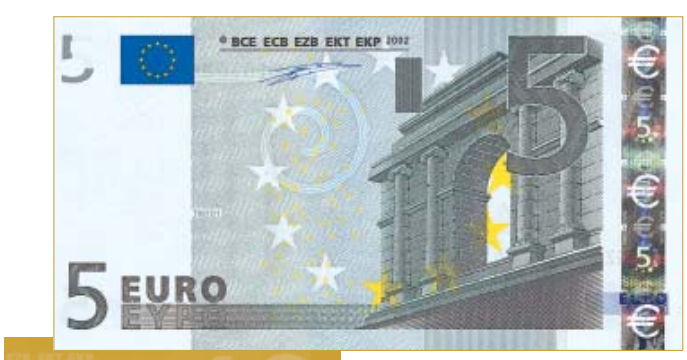

In 2006 all ECB

publications

feature a

motif taken

$€ 5$ banknote.

This paper can be downloaded without charge from http://www.ecb.int or from the Social Science Research Network electronic library at http://ssrn.com/abstract_id $=923384$

\footnotetext{
I The views expressed in this paper are those of the authors and do not necessarily reflect those of the European Central Bank. We are grateful to participants at a seminar at the Hong Kong Monetary Authority, the Bank of Finland Workshop on Emerging Markets in Saariselkä and the Ninth International Convention of the East Asian Economic Association, Hong Kong - in particular, the discussant Takatoshi Ito - for their comments. In addition, we would like to thank an anonymous referee for the very useful suggestions and comments. 2 Finance Department, Carroll School of Management, Boston College, I 40 Commonwealth Avenue, Chestnut Hill, MA 02467-3808, USA; e-mail: moneta@bc.edu 3 External Developments Division, European Central Bank, Kaiserstrasse 29, 603 II Frankfurt am Main, Germany; e-mail: rasmus.rueffer@ecb.int
} 
(C) European Central Bank, 2006

\section{Address}

Kaiserstrasse 29

60311 Frankfurt am Main, Germany

\section{Postal address}

Postfach 160319

60066 Frankfurt am Main, Germany

\section{Telephone}

+496913440

\section{Internet}

http://www.ecb.int

\section{Fax}

+496913446000

\section{Telex}

$411144 \mathrm{ecb} d$

All rights reserved.

Any reproduction, publication and reprint in the form of a different publication, whether printed or produced electronically, in whole or in part, is permitted only with the explicit written authorisation of the ECB or the author(s).

The views expressed in this paper do not necessarily reflect those of the European Central Bank.

The statement of purpose for the ECB Working Paper Series is available from the ECB website, http://www.ecb.int.

ISSN 1561-0810 (print)

ISSN 1725-2806 (online) 


\section{CONTENTS}

Abstract

Non-technical summary

1. Introduction

2. Stylised facts about East Asian trade and its implications

3. The model

4. Data

5. A common dynamic factor model of East Asian growth

6. Multiple factors and sub-groups

7. Comparison with some European countries

8. The drivers of co-movement: An analysis of GDP components

9. Structural factors underlying synchronisation I: Intra-regional spill-over effects

10. Structural factors underlying synchronisation II: Common exogenous shocks

11. Structural factors underlying synchronisation III: Inter-regional linkages

12. Conclusion

Appendix

Bibliography

European Central Bank Working Paper Series 


\begin{abstract}
Against the background of the rapid inter- and intraregional integration of East Asia, we examine the extent and nature of synchronisation of business cycles in the region. We estimate various specifications of a dynamic common factor model for output growth of ten East Asian countries. A significant common factor is shared by all Asian countries considered, except China and Japan. The degree of synchronisation has fluctuated over time, with an upward trend particularly evident for the newly industrialised countries. Synchronisation appears to mainly reflect strong export synchronisation, rather than common consumption or investment dynamics. Cross-country spill-over effects explain only a small part of the comovement in the region. More importantly, a number of exogenous factors, such as the price of oil and the JPY-USD exchange rate, play an important role in synchronising activity. In addition, economic linkages with Europe and North America may also have contributed to the observed synchronisation.
\end{abstract}

Keywords: business cycles synchronisation, East Asia, dynamic factor model

JEL classification: E30, F00 


\section{Non-technical summary}

Over recent decades, East Asia has undergone a process of rapid economic expansion accompanied by increasing economic - and, in particular, trade - integration both within the region and with the global economy. An important question is whether this increasing inter and intra-regional economic integration has resulted in a higher degree of synchronisation of business cycles and in strong growth links between the countries of the East Asian region and, possibly, with the rest of the world. In addition to being relevant for macroeconomic policy-making in general, the issue of synchronisation has also important implications in the context of ongoing discussions about the possibility of greater monetary co-operation within the East Asian region, which have experienced a revival in the wake of the Asian crisis. On theoretical grounds, the direction of the relationship between economic integration and business cycle comovement is ambiguous. For instance, regarding external trade, greater demand side spill-over effects may be offset by increased production specialisation and thus exposure to different sector-specific shocks. In general, it appears that a higher share of intra-industry trade makes it more likely that the demand side effects dominate, as any specialisation is likely to occur within the same industries. Although one might therefore expect that the degree of business cycle co-movement in East Asia should be relatively high, and possibly increasing over time, given the prevalence of intra-industry trade, it ultimately remains an empirical question.

Against this background, the first goal of this paper is to examine whether and to what extent real activity in East Asia is driven by a joint business cycle. For that purpose, we estimate various specifications of a dynamic common factor model for output growth of ten East Asian countries from 1993-2005, and a longer sample from 1975-2005 for the newly industrialised countries (Hong Kong, Korea, Singapore and Taiwan). We find that a significant common factor is shared by all ten Asian countries considered, except China and Japan. Moreover, the degree of synchronisation has fluctuated significantly over time, with an upward trend particularly evident for the newly industrialised countries.

In general, the co-movement found in the data may reflect either the similar effects of common shocks across countries or, alternatively, the synchronising effect of shocks in one country spilling over to other countries. As the distinction between these two causes of synchronisation is of crucial importance for policy purposes and for assessing the impact of increased globalisation, the second main objective of the paper is to investigate the driving forces behind the observed co-movement in East Asian activity. As a first step, we analyse the main GDP components and compare their cross-country co-movement with that of overall GDP. This analysis shows that a considerable part of the co-movement between East Asian economies appears to be the result of co-movement in exports, thus suggesting an important role for common external shocks. In fact, even Japan and China exhibit a considerable degree of co-movement with the rest of Asia with respect to their exports. In contrast, in the case of Japan, neither private consumption nor investment show any tendency to co-move with these demand components in the rest of Asia, thus explaining the relative independence of the overall Japanese business cycle.

As a second step towards understanding the factors underlying synchronisation, we try to disentangle the relative importance of cross-country spill-over effects and common shocks more directly. We modify the 
dynamic factor model to incorporate cross-country interactions. For the newly industrialised countries, for which a longer sample period is available, we find evidence of significant inter-country spill-over effects, which are found to account for around one fifth of the observed co-movement. In order to better understand the nature of the quantitatively more important common shocks, the paper assesses the ability of a number of potential common exogenous factors to explain the evolution of the East Asian common factor. The analysis suggests that exogenous factors may indeed provide an important explanation for synchronisation. Oil and commodity price movements and changes in the USD/JPY exchange rate appear to be particularly relevant in that respect, while G7 activity, global equity prices and US long and shortterm interest are found to be of less importance, largely restricted to the newly industrialised countries.

Finally, we assess to what extent interactions between the East Asian region and Europe and North America can account for the observed co-movement within the region, as might be suggested by the high degree of synchronisation in East Asian exports. For that purpose we extend the sample of countries to include the United States, Canada and a number of European countries. Furthermore, we introduce areaspecific dynamic factors, which are allowed to interact with each other. We find that the Asian region is only weakly affected by developments in the other two regions, while the Asian region seems to exert some influence on European growth and, to a lesser extent, on North American growth. However, to the extent that Asian producers are forward-looking and anticipate future growth developments in the other two regions, the apparent lagged effect of Asia on the other regions may in fact reflect a causal relationship in the other direction, with Asian exporters adjusting their production levels today in order to be able to meet export demand tomorrow with limited swings in inventories. 


\section{Introduction}

In recent decades, Asia has become increasingly integrated with the global economy. At the same time, economic integration within Asia has also progressed at an impressive speed. This is evidenced, for example, by the rapid increase in intra-regional trade flows, which partly reflect the increasing internationalisation of the production process. In particular, China has emerged as a major assembly and processing centre, thereby increasing intra-regional trade and financial flows, while simultaneously strengthening the links between countries within the region. This process of increasing inter and intraregional integration is likely to have an effect on the growth dynamics of the East Asian region and, in particular, on the degree of synchronisation within the region and between the region and the rest of the world. From a theoretical perspective, the effect of greater trade integration on business cycle synchronisation is ambiguous. Greater demand side spill-over effects may be offset by increased production specialisation and thus exposure to different sector-specific shocks. In general, it appears that the higher the share of intra-industry trade between countries, the more likely that increased trade will lead to greater synchronisation. Although one might therefore expect that the degree of business cycle comovement should increase with integration in East Asia given its trade structure, it ultimately remains an empirical question whether and to what extent this is the case.

The issue of synchronisation is also relevant in the context of ongoing discussions about the possibility of greater monetary co-operation within the East Asian region - possibly culminating in a full-fledged monetary union with common currency - which have been revived in the wake of the Asian crisis. Taking the "optimal currency area" argument of Mundell (1961) as a starting point, some recent studies have therefore looked at the business cycle correlation between countries in the Asia-Pacific region in order to examine the desirability of a regional currency union. ${ }^{1}$ Similar to these studies, we also attempt to analyse the synchronisation characteristics of East Asian growth dynamics in greater detail. For that purpose we construct a parametric dynamic common factor model to extract common growth features from GDP and industrial production data.

Going a step further compared to most other studies, we also investigate the driving forces behind the comovement in activity. First, we analyse the main GDP components and compare their cross-country comovement with that of overall GDP. This exercise provides some initial insights in the sources of comovement. In general, co-movement can be produced by two main factors: first, countries can be exposed to common shocks, to which they respond in a similar fashion; second, initially idiosyncratic shocks in one country can spill over to other countries due to trade and financial linkages. In the case of East Asia, both of these factors could potentially play an important role. On the one hand, common shocks could, for example, stem from the large trade exposure to the US or Europe or the concentration of production in the information technology sector. Spill-over effects as a source of synchronisation, on the other hand, may be the result of the strong intra-regional trade linkages in Asia. To disentangle these two effects we introduce explicitly cross-country spill-over effects into the dynamic factor model. This removes that part

\footnotetext{
${ }^{1}$ See, for example, Bayoumi and Eichengreen (1994), Loayza et al. (2001) and Crosby (2003).
} 
of the common factor that is due to spill-over effects. A comparison of the models with and without spillover effects can be conducted, thereby providing an assessment of the quantitative importance of this factor in explaining intra-regional synchronisation. In addition, we investigate econometrically the extent to which the estimated common factor can be explained by various common shocks such as oil and overall commodities prices, global financing conditions and the variation in the exchange rate between the US dollar and the Japanese Yen. Furthermore, we assess to what extent interactions of the East Asian region with Europe and North America can help to account for the observed co-movement within the region. For that purpose we extend the dynamic factor model to include several area factors, with the possibility of lagged interaction between the different area factors. The main contribution of the current paper is to apply the dynamic factor model developed in Monfort et al. (2003) to the Asian economies. To date, they have received only relatively limited attention in the synchronisation literature, despite their dynamism and the special relevance of the issue for the region. Moreover, this paper goes beyond the analysis conducted in Monfort et al. (2003) by attempting to identify the factors which drive the comovement. To that end, the paper contains an analysis of disaggregated GDP data by spending component and, in addition a wide range of variables are examined in an effort to understand the factors driving the common Asia factor.

The analysis shows that a single common dynamic factor captures a substantial part of the output dynamics of Asian countries - with the exception of China and Japan. Furthermore, the degree of synchronisation has increased over the past two decades in particular for the newly industrialised countries (NICs), with the Asian crisis explaining only part of this increase. Synchronisation appears to mainly reflect strong export synchronisation, rather than common consumption or investment dynamics. Studying the determinants of the synchronisation, we find some significant inter-country spill-over effects among the NICs. In addition, the analysis of possible exogenous factors suggests that oil prices may have played some role in synchronising activity, especially for the NICs more recently, while activity in the rest of the world and international financing conditions are found to be less important. In addition, the JPY-USD exchange rate appears to be an important driving force of the Asian business cycle, especially in the case of the NICs. Regarding the interaction with other regions the analysis shows that the Asiaspecific factor interacts with a European and a North-American factor. Although the effects seem to run mainly from East Asia to other regions, this may actually reflect causation in the other direction as forward-looking behaviour of East Asian exporters may anticipate future demand developments in other regions.

The paper is structured as followed: Section 2 reviews some stylised facts about the East Asian region, with a particular focus on intra-regional and cross-regional trade links. In addition, this section provides a discussion of the theoretical links between integration and synchronisation and offers a selective overview of the relevant literature. Section 3 lays out the empirical modelling strategy and Section 4 provides some details about the data. The remaining part of the paper is thematically divided into two major components: Sections 5 to 7 assess the degree and structure of synchronisation within East Asia, while Sections 8 to 11 investigate the underlying factors behind the synchronisation. Concretely, in Section 5, we present the results from the model with one common factor for East Asian GDP and industrial production growth. In Section 6, we check the robustness of these results by allowing for multiple common factors and by trying 
to identify stable sub-groups of countries within the region sharing separate growth dynamics. In order to provide some benchmark for the degree of synchronisation within East Asia, section 7 contains a comparison with a similar analysis for a sub-group of countries in the euro area. Section 8 presents an initial investigation of the underlying factors behind East Asian synchronisation in the form of a more disaggregated analysis using different GDP demand components (exports, consumption, and investment) and sectoral information on the supply side. Section 9 contains an extension of the model, which allows for cross-country spill-over effects in addition to the common factor. Section 10 considers possible common shocks that might underlie the observed synchronisation. In a similar vein, Section 11 addresses the interaction of different area factors, which may provide an alternative explanation of similar dynamics across Asian countries. Finally, Section 12 offers some concluding comments.

\section{Stylised Facts about East Asian Trade and Its Implications}

Trade links have the potential to play an important role in business cycle synchronisation across countries. Therefore, this section provides some stylised facts about East Asian trade, highlighting the special importance of these links in the case of East Asia. Over the past two decades, East Asia has experienced a substantial expansion in trade. In 2001, it constituted the largest trading area in the world accounting for $18.5 \%$ of world merchandise trade. This reflects both the growth in trade with countries in other regions as well as the rapid increase in trade within the region. The potential for trade flows to affect overall GDP developments especially in Asia is suggested by the high degree of openness of the countries in the region, as for example measured by the share of exports in GDP. While the average value of this share between 1999 and 2002 has been 14\%, 8\% and 11\% for the euro area, the US and Japan respectively, it reached $31 \%$ for the East Asian countries considered in this paper.

Regarding the trade links with other countries outside the group, East Asia has particularly strong trading ties with Japan, the US and the euro area (see Table 1). Almost 1/3 of the region's exports are destined for the US (29\%), with another 1/3 going to the euro area (16\%) and Japan (17\%). As documented by Isogai and Shibanuma (2000), these links have strengthened considerably, with significant shifts in the geographical structure. In particular, East Asian exports to the US and imports from Japan have increased particularly strongly, reflecting partly the internationalisation of the production process. Rather than exporting directly to the US, Japanese firms increasingly export intermediate goods to East Asia for assembly, with the final goods then being directly exported from East Asia to the US. This shift in the trading and production relationships within East Asia is, of course, likely to increase East Asia's vulnerability to shocks outside the region. As such shocks may affect several countries in a similar manner, this could also lead to an increased synchronisation of activity within the region. 


\begin{tabular}{|c|c|c|c|c|c|c|c|c|}
\hline \multicolumn{9}{|c|}{$\begin{array}{l}\text { Inter-regional trade } \\
\text { (As \% of total regional imports/exports, average 1999-2002) }\end{array}$} \\
\hline & \multicolumn{2}{|c|}{ NJA } & \multicolumn{2}{|c|}{ Euro Area } & \multicolumn{2}{|c|}{ Japan } & \multicolumn{2}{|c|}{$\underline{\text { US }}$} \\
\hline & Exports & Imports & Exports & Imports & Exports & Imports & Exports & Imports \\
\hline$\underline{\text { NJA }}$ & -- & -- & $16 \%$ & $13 \%$ & $17 \%$ & $25 \%$ & $29 \%$ & $18 \%$ \\
\hline Euro Area & $8 \%$ & $12 \%$ & -- & -- & $3 \%$ & $6 \%$ & $17 \%$ & $14 \%$ \\
\hline Japan & $37 \%$ & $38 \%$ & $12 \%$ & $10 \%$ & -- & -- & $28 \%$ & $18 \%$ \\
\hline US & $16 \%$ & $22 \%$ & $15 \%$ & $14 \%$ & $8 \%$ & $11 \%$ & -- & -- \\
\hline
\end{tabular}

Source: IMF, Direction of Trade Statistics, CEIC (for Taiwan)

Notes: NJA = China, Hong Kong, Indonesia, Malaysia, the Philippines, Singapore, South Korea, Taiwan and Thailand.

At the same time, links within the region have strengthened considerably as well. As shown in Chart 1 , intra-regional trade as a share of GDP has increased continuously from around 7\% in the period 1985-87 to almost $14 \%$ in $1995-98$. Thereafter this trend has continued, reaching $16 \%$ in the period $1999-2002$ (not shown in the chart). In comparison, the importance of intra-regional trade is much less pronounced in the Western Hemisphere, with intra-regional trade shares below 5\% in the case of NAFTA and Mercosur. While starting out at a lower level in the mid-1980s, Asia has now overtaken the euro area with respect to the ratio of intra-regional trade to GDP.

\section{Chart 1}

Relative size of intra-regional trade compared to GDP

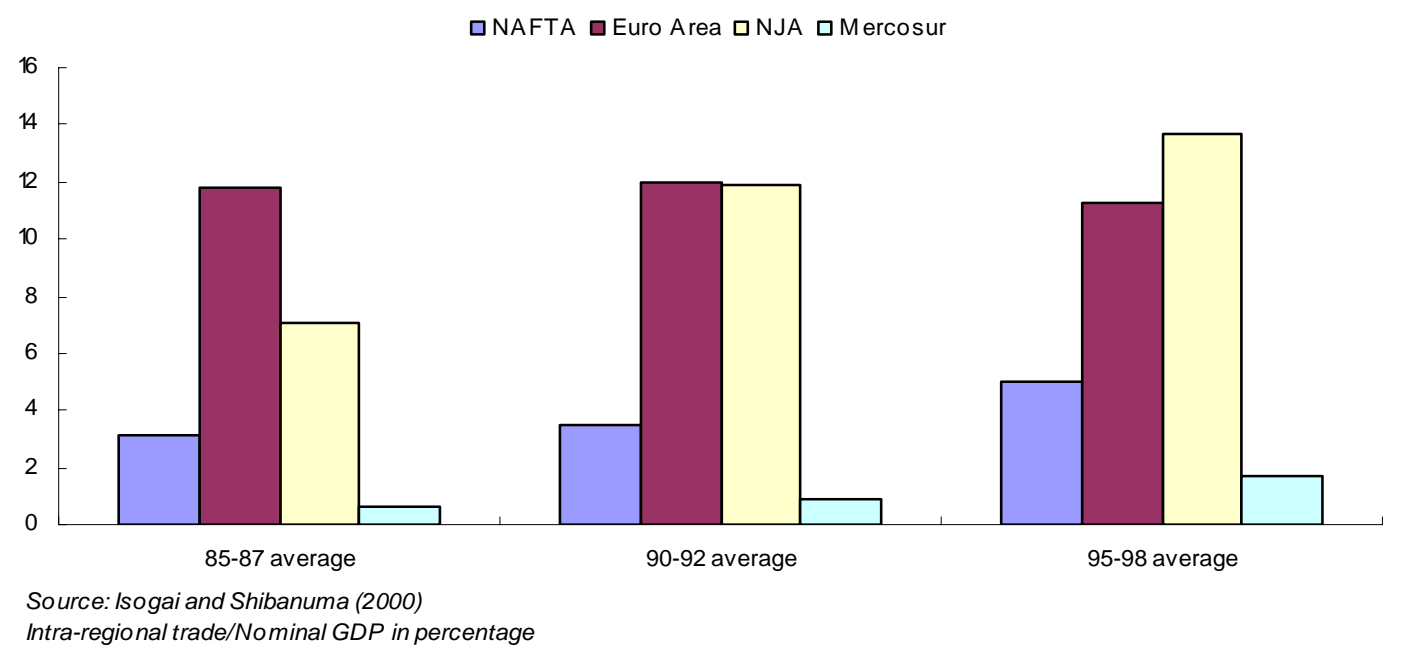


An important question that arises in this context is to what extent the increasing economic integration of East Asia - both internally and externally - has resulted in strong growth links between the countries of the East Asian region and with the rest of the world. On theoretical grounds, the direction of the relationship between two countries' economic integration and their business cycle co-movement is ambiguous. Regarding external trade, closer integration should, on the one hand, lead to stronger spillovers of demand shocks from one country to the other, thereby increasing co-movement (e.g. Frankel and Rose, 1998). In addition, positive spill-overs on the supply side may reinforce any demand-side effects. For example, Canova and Dellas (1993) developed a small dynamic stochastic general equilibrium model of the world economy in which productivity shocks in the production of traded intermediate goods produced positive output co-movement across countries. On the other hand, trade integration may lead to specialisation in production, thereby reducing the symmetry of the impact of industry-specific shocks on the two countries, resulting in reduced co-movement (see e.g. Krugman, 1993, and Kose and Yi, 2002). The specialisation argument is particularly relevant in the case of inter-industry trade, but should play less of a role in the case of intra-industry trade, as specialisation in the latter case occurs within the same industry (Frankel and Rose, 1998). ${ }^{2}$ A similar argument can be made about financial integration. As financial integration allows greater risk sharing between countries, it permits greater specialisation of a country's production structure. Although greater specialisation increases the volatility of domestic production, the availability of international risk diversification through financial integration helps offset the impact on domestic income (e.g. Kalemli-Ozcan et al., 2001). In addition to these effects through financial and trade integration, greater economic integration may also lead to higher synchronisation through increased knowledge spillovers (e.g. Coe and Helpman, 1995) or through increased policy similarity (e.g. Frankel and Rose, 1998).

Given the ambiguity of economic theory on this issue, a large empirical literature has developed to study the effect of trade and financial linkages on business cycle synchronisation. Frankel and Rose (1998) find a strong positive relationship between trade integration and business cycle correlation by regressing bilateral business cycle correlation on bilateral trade intensity for a sample of OECD countries. Similarly, Clark and von Wincoop (2001) provide evidence that the lower synchronisation of European business cycles compared to U.S. Census regions reflects the lower level of trade among European countries. Imbs (2004) confirms these findings of a strong positive effect of trade integration on business cycle synchronisation for a sample of 24 industrialised countries, with the effect being largely accounted for by intra-industry trade. Garcia Herrero and Ruiz (2005) provide additional evidence for a positive link between trade and synchronisation, which is however small in economic terms and only due to the indirect effects on increased similarity in economic structures. Regarding financial linkages, Imbs (2004) finds that financial integration has a positive effect on synchronisation, with the direct positive effect being stronger than the negative indirect effect running through increased specialisation. Although Garcia Herrero and Ruiz (2005) confirm the positive link between finance and synchronisation, they attribute this

\footnotetext{
${ }^{2}$ The discussion on the synchronising effect of trade integration is closely related to the optimal currency area discussion. While it is generally accepted that a monetary union leads to an increase in trade among the members of the union, it is less clear whether this implies that the monetary union thereby moves ex post closer to satisfying the conditions for an optimal currency area or not, which depends crucially on the interrelationship between trade and synchronisation.
} 
effect entirely to the indirect effect on increased similarities in economic structures, thus contradicting the findings by Imbs on the indirect effect. Supporting the potential importance of indirect effects, KalemliOzcan et al. (2001) show that higher specialisation in production translates into a reduction of synchronisation. Overall the empirical studies tend to provide evidence of a positive link between economic integration and synchronisation, especially for advanced economies. For emerging and developing economies the evidence appears to be more scant and somewhat more mixed however.

Although Asia has been one of the most dynamic regions in terms of increasing inter and intra-regional integration, it has received only very limited attention in the synchronisation literature so far. In the case of Asia, trade integration has had an important intra-industry dimension, which has become more important during the last decade. This reflects the increasing distribution of the production chain across different countries in the region according to their respective comparative advantage in different stages of the production process. ${ }^{3}$ Therefore, one might expect to find stronger co-movement across countries compared to other regions where inter-industry trade plays a more important role. In fact, Shin and Wang (2004) find that the strength of intra-industry trade links between Korea and its individual trading partners is the most important determinant of output correlation with the trading partner, while the overall volume of trade proves considerably less relevant. In a related paper, Shin and Wang (2003) also conclude that intra-industry trade is the major channel through which the business cycles of East Asian economies become more synchronised. In addition, the authors, using annual GDP data for the period 1976-1997, do not find clear evidence that the average bilateral correlation has increased over time.

Abeysinghe and Forbes (2005) analyse trade linkages between Asian countries augmented by "outputmultiplier effects", i.e. the indirect effect a shock to one country can have through its impact on activity in other trading partners. The authors find important linkages between Asian countries, with the strength of the effects not being directly related to the strength of bilateral trading relationships, as indirect multipliers prove to be empirically important. Using principal components analysis, Selover (1999) finds evidence for a shared business cycle among the ASEAN countries. However, results from VAR estimations trying to capture the interaction between pairs of countries provide only weak evidence of business cycle transmission between ASEAN countries and between ASEAN and its major trading partners outside the region. In a related paper, Selover (2004) focuses more narrowly on the economic links between Japan and Korea using a structural VAR methodology. He finds that industrial production in the two Asian countries is moderately synchronised and that causation runs from Japan to Korea, but not vice versa. In addition, he provides some evidence that the transmission from Japan to Korea has become stronger over time. Girardin (2002) applies a Markov-switching framework to analyse business cycle synchronicity between Japan and three Asian countries, using industrial production data. ${ }^{4}$ In combination with a VAR framework, he finds evidence for a common growth cycle among the four countries. Rather than focusing on bilateral relationships between countries, as many of the studies do, we are more interested in taking a multilateral approach and assessing directly whether and to what extent

\footnotetext{
${ }^{3}$ For a more detailed discussion, see Isogai, Morishita and Rüffer (2002).

${ }^{4}$ The countries are Korea, Malaysia and Singapore, with the choice of countries determined by data availability.
} 
activity in Asia is driven by a shared business cycle. In addition, we would like to identify spill-over effects between countries and regions.

\section{The Model}

A number of different methodologies have been applied in the literature to study the degree of synchronisation between economic variables. The most basic approach is a correlation analysis, which has been used in a large number of studies (e.g. Baxter and Stockman, 1989, Backus et al., 1992, and Bordo and Helbling, 2003). As noted by Monfort et al. (2003), a correlation analysis is associated with two main drawbacks: First, it does not allow for a separation of idiosyncratic components and common co-movement and is not suited to study the issue of cross-country spill-over effects and common shocks. Second, it is basically a static analysis that fails to capture any dynamics in the co-movement. In addition, we are more interested in investigating the degree of region-wide co-movements, rather than bilateral ones.

An alternative measure of synchronisation in the case of business cycles is the concordance correlation developed by Harding and Pagan (2002). This measure assesses whether two economies are in the same phase (expansion or recession) and thus the measure relies on the identification of turning points in the cycle. Bordo and Helbling (2003) among others have used this approach. Lumsdaine and Prasad (1997) use time-varying weights constructed on the basis of a GARCH specification to extract a common component from a cross-section of industrial production. Intuitively, a country receives a lower weight if the variance of its production is large relative to that of other countries indicating an idiosyncratic development. While these methodologies may provide an estimate of the common component they do not identify the various shocks and do not model the interactions between the variables explicitly.

A more sophisticated approach which is increasingly being employed is the use of factor models. The basic underlying idea is that common movement in a cross-section of $n$ stationary time series $\mathrm{Y}_{\mathrm{t}}$ (e.g. GDP growth in different countries) can be captured by $k$ common factors $(k<<n)$, unobservable variables influencing the evolution of all series.

$$
Y_{t}=B Z_{t}+\xi_{t},
$$

where $\mathrm{B}$ is an $\mathrm{n} \times \mathrm{k}$ matrix of loading coefficients, $\mathrm{Z}_{\mathrm{t}}$ is a $\mathrm{k} \times 1$ vector of common factors and $\xi_{\mathrm{t}}$ is an $\mathrm{n}$ dimensional stationary process. In strict factor models, the $\xi_{\mathrm{t}}$ are assumed to be uncorrelated, whereas approximate factor models allow for some correlation among the idiosyncratic error terms. Such a static factor model is for example employed by Bordo and Helbling (2003). The main drawback of using a static factor model is that it does not allow for dynamics in the relationship between the economic variables and the factors. Therefore, many studies have used instead variants of a dynamic factor model: 


$$
Y_{t}=\sum_{i=1}^{\infty} B_{i} Z_{t-i}+\xi_{t}=B(L) Z_{t}+\xi_{t}
$$

Assuming that $\mathrm{Z}_{\mathrm{t}}$ can be expressed as a moving average process, the $\mathrm{Y}_{\mathrm{t}}$ can be written as consisting of common and idiosyncratic shocks, $\eta_{\mathrm{t}}$ and $\xi_{\mathrm{t}}$ respectively:

$$
Y_{t}=B(L) C(L) \eta_{t}+\xi_{t}=B^{*}(L) \eta_{t}+\xi_{t}
$$

where $Z_{t}=C(L) \eta_{t}$ and $\eta_{t}$ are the k uncorrelated common shocks. It is assumed that the $\eta_{t}$ and $\xi_{t}$, and thus the common and the idiosyncratic components of $\mathrm{Y}_{\mathrm{t}}$, are orthogonal to each other. For identification purposes the variance of the common shocks is standardised to be 1, i.e.

$$
V[\eta]=I d(k)
$$

A generalised or approximate dynamic factor model, which allows for correlation among the $\xi_{\mathrm{t}}$, has been recently applied in the literature (e.g. Stock and Watson, 1998, Malek Mansour 2003, Lippi and Thornton, 2004).

In this paper we choose a slightly different specification of the dynamic factor model, following Monfort et al. (2003). The model assumes that the $Y_{t}$ can be modelled as consisting of a country-specific autoregressive component of order one ${ }^{5}, A Y_{t-1}$, k unobservable factors $Z_{1, t}, \cdots, Z_{k, t}$ common to all the series and an idiosyncratic white noise error term $\varepsilon_{\mathrm{t}}$. The common factors, in turn, are assumed to follow a first-order autoregressive process. This linear state-space model can be written as follows ${ }^{6}$ :

$$
\begin{aligned}
& Y_{t}=A Y_{t-1}+B Z_{t}+\varepsilon_{t} \\
& Z_{t}=D Z_{t-1}+\eta_{t}
\end{aligned}
$$

where $\varepsilon_{t}$ and $\eta_{t}$ are independent Gaussian white noise terms. The $B$ matrix of factor loadings or sensitivities measures the instantaneous impact of the common factors on each series $Y_{i}{ }^{7}$ The variance-

\footnotetext{
${ }^{5}$ The choice of the order of the autoregressive process for $Y_{t}$ is justified not only by reasons of reduction of parameters to be estimated but also by the Box-Jenkins identification method which, in general, suggests a lag 1 for the series used in this paper. We tried also to estimate the model using 2 lags but the log-likelihood either does not improve or improves, but not significantly.

${ }^{6}$ See Monfort et al., ibid., for more details.

${ }^{7}$ By re-writing the model slightly, it can be seen that it represents a special case of the more general dynamic factor model in equation (3):

$$
Y_{t}=(I-A L)^{-1} B(I-D L)^{-1} \eta_{t}+(1-A L)^{-1} \varepsilon_{t}
$$

where $(I-A L)^{-1} B(I-D L)^{-1}=B^{*}(L)$ and $(1-A L)^{-1} \varepsilon_{t}=\xi_{t}$.
} 
covariance matrix of the disturbances $\varepsilon$ is assumed to be diagonal, with

$$
V[\varepsilon]=\left[\begin{array}{ccc}
\sigma^{2}{ }_{1} & & 0 \\
& \ddots & \\
0 & & \sigma^{2}{ }_{n}
\end{array}\right],
$$

where $\sigma^{2}{ }_{i}$ denotes $V\left[\varepsilon_{i}\right]$. The specification is thus based on the coincident indicator model by Stock and Watson (1991) and resembles the one by Norrbin and Schlagenhauf (1996), who also allow for lagged dependent variables in the measurement equation in a multi-country industry-level model. Similarly, Gregory et al. (1997) and Kose et al. (2003) also employ state-space representations of the dynamic factor model without, however, including the lagged dependent variable as a regressor. Rather than capturing the idiosyncratic error dynamics through the lagged $\mathrm{Y}$ they model the idiosyncratic errors directly as AR(1) and AR(p) processes respectively.

One of the advantages of the chosen specification is that it is fairly flexible and allows for distinguishing between common shocks and cross-country spill-over effects, which may also give rise to synchronisation among countries. While in most other specifications any co-movement is attributed entirely to the common factors irrespective of its origin, the effects of spill-overs can be to some extent isolated in the above specification by allowing off-diagonal elements of the A matrix to be non-zero. ${ }^{8}$ In addition to cross-country spill-over effects, cross-regional spill-overs can also be considered through the inclusion of multiple region-specific factors and a non-diagonal D matrix. In that respect it improves, for example, on the study by Gregory et al. (1997). In the approximate or generalised factor models a certain degree of correlation between the idiosyncratic components is permitted in order to "leave some room for local interaction” (Malek Mansour, 2003, p. 227). In contrast, we try to capture such interaction between the variables parametrically through the A matrix, which permits direct cross-country spill-over effects, and through the specification of region-specific factors.

The unknown vector of parameters $\theta$ is finite dimensional and, therefore, the model is parametric and can, in principle, be estimated through Kalman filtering. ${ }^{9}$ As the number of time series is relatively limited, the maximum likelihood approach does not run into computational problems as in some other applications. For example, Kose et al. (2003) devise a Bayesian estimation strategy to estimate a dynamic factor model for a cross-section of 60 countries including 3 series per country. Taking a different route, Stock and Watson (2001) and Forni and Reichlin (1998) propose the use of static and dynamic principal components estimation respectively for the estimation of dynamic factor models for large cross-sections of time series.

\footnotetext{
${ }^{8}$ Strictly speaking this only applies to lagged spill-over effects as the A matrix is associated with the term $\mathrm{Y}_{\mathrm{t}-1}$. Thus any spillover effects occurring within the same period would still be included in the common factor.

${ }^{9}$ The Kalman filter provides at each step $\mathrm{k}$ the likelihood function for $\mathrm{k}+1$ conditional on information given at $\mathrm{k}$. Therefore, the log-likelihood function for the entire sample can be constructed as a by-product of the Kalman filtering. As in Monfort et al. (2003), we use a two-step procedure for the purpose of maximisation: First, we apply the Expectations Maximisation (EM) algorithm, which generates estimates in the region of the maximum reasonably quickly even from poor starting values. However, the EM algorithm does not have quadratic convergence properties and thus converges only slowly in the vicinity of the maximum. Moreover, the EM algorithm does not provide an estimate of the information matrix. In a second step, we therefore apply the numerical BFGS maximisation algorithm provided by GAUSS. We calculate the information matrix based on the results by Engle and Watson (1981).
} 
More recently, Kapetanios and Marcellino (2003) have suggested a different method based on the state space representation and using subspace algorithms from engineering.

\section{Data}

We use quarterly real GDP data for 10 Asian countries. The sample includes Japan, China, Singapore, Hong Kong, Taiwan, South Korea, Thailand, Malaysia, Indonesia and the Philippines. In addition, we use some components of real GDP: exports, private consumption and gross fixed capital formation. In this case we do not have quarterly data for China. The data have been seasonally adjusted using the X12ARIMA method. For this analysis we use log differenced data in order to render the data stationary.

Quarterly data for the 10 Asian countries are available from different starting points. In our estimation we use a sample from 1975:Q1 to 2005:Q3 for Japan, Hong Kong, Singapore, Taiwan and South Korea and from 1993:Q1 for the other countries. ${ }^{10}$ The main source of the data is the Global Insight database, which has been complemented with series coming from IMF, BIS and OECD databases. ${ }^{11}$

Industrial production data are also obtained via Global Insight with the following ultimate sources: Japan - Ministry of Trade and Industry, China - WIS Indicator, Singapore - Monthly Digest of Statistics, Taiwan - Council of Economic Planning and Developments, Korea - Bank of Korea, Thailand - Bank of Thailand, Indonesia - Central Bureau of Statistics, Philippines - National Statistics Coordination Board, Malaysia - Department of Statistics. The longest sample available for all countries ranges from 1992:10 to 2005:12, with data for the four Newly Industrialised Countries (NICs) being available starting only in 1989:1, due to a lack of longer data series in the case of Singapore. The data have been seasonally adjusted using the X12ARIMA method.

As a preliminary exercise, Tables 2, 4 and 5 provide information on the bilateral correlation between the GDP growth series of the various East Asian countries. As shown in Table 2, GDP growth within East Asia exhibits a considerable degree of co-movement. In particular, Hong Kong, Indonesia, Thailand and Malaysia have a correlation coefficient above 0.4 with at least four other countries in the region. China and Japan stand out as countries with very low or even negative correlation coefficients, which never reach 0.4. To offer some perspectives on the magnitude of these coefficients, Table 3 presents the correlation coefficients among eight euro area countries and between the US and Canada. The correlation coefficients are in general lower than in Table 2.

\footnotetext{
${ }^{10}$ For exports, quarterly data for Singapore were available only since 1975:Q1. For Japan, Hong Kong, Taiwan data are available since 1973:Q1, but in order to cover also Singapore we start our estimation sample in 1975:Q1. The sample range for the other countries was constrained by the availability of data for Thailand and Indonesia, which start in 1993:Q1. The starting dates for the other series are: the Philippines 1981:Q1, China 1987:Q1, Malaysia 1990:Q1. In all cases, we effectively lose one observation at the beginning of the sample through differencing of the data.

${ }^{11}$ The dataset has been compared with that used by Cerra and Saxena (2003) and the series are similar.
} 


\section{Table 2}

Cross-correlations among real GDP growth rates

(From 1993:Q2 to 2005:Q3)

\begin{tabular}{|c|c|c|c|c|c|c|c|c|c|c|}
\hline & Jap & Chi & Sin & HK & Tai & Kor & Tha & Mal & Ind & Phi \\
\hline \multicolumn{11}{|l|}{ Japan } \\
\hline China & 0.143 & & & & & & & & & \\
\hline Singapore & 0.205 & 0.105 & & & & & & & & \\
\hline Hong Kong & 0.305 & 0.001 & 0.554 & & & & & & & \\
\hline Taiwan & 0.253 & 0.045 & 0.627 & 0.551 & & & & & & \\
\hline Korea & -0.023 & 0.201 & 0.273 & 0.365 & 0.045 & & & & & \\
\hline Thailand & 0.304 & -0.080 & 0.555 & 0.540 & 0.408 & 0.466 & & & & \\
\hline Malaysia & 0.178 & 0.130 & 0.420 & 0.476 & 0.300 & 0.567 & 0.717 & & & \\
\hline Indonesia & 0.099 & -0.028 & 0.312 & 0.382 & 0.054 & 0.582 & 0.661 & 0.558 & & \\
\hline Philippines & 0.023 & 0.109 & 0.388 & 0.442 & 0.313 & 0.346 & 0.488 & 0.437 & 0.505 & \\
\hline
\end{tabular}

\section{Table 3}

Cross-correlations among real GDP growth rates

(From 1993:Q2 to 2005:Q3)

\begin{tabular}{lllllllll}
\hline \hline BE & DE & ES & FI & FR & GR & IT & NL & CAN \\
\hline
\end{tabular}

Belgium

Germany $\quad 0.389$

Spain $\quad 0.256 \quad 0.149$

Finland $\quad 0.091 \quad 0.050 \quad 0.273$

France $\quad 0.246 \quad 0.224 \quad-0.004 \quad 0.326$

$\begin{array}{llllll}\text { Greece } & -0.077 & -0.153 & -0.003 & 0.084 & -0.081\end{array}$

$\begin{array}{lllllll}\text { Italy } & 0.394 & 0.055 & 0.318 & 0.451 & 0.373 & -0.045\end{array}$

$\begin{array}{llllllll}\text { Netherlands } & 0.400 & 0.475 & 0.187 & 0.099 & 0.295 & -0.126 & 0.174\end{array}$

USA

As the Asian common sample is limited to a relatively short time period starting in 1993, the relatively high degree of bilateral co-movement may be influenced strongly by the Asian crisis, which affected a number of countries in the region in a similar way. The correlation among the NICs and Japan, for which a longer sample period is available, is certainly lower if one takes a longer term view beginning in 1975 (see Table 4) and even lower if one restricts attention to the pre-crisis period (see Table 5). While the average correlation among the 5 countries for the post-1993 sample is 0.36 , it declines to 0.23 for the entire sample and to 0.08 for the pre-crisis sample until the end of 1996. Although the shared crisis experience may thus account for a significant part of the regional co-movement, other factors such as the increasing economic integration of the region may also have led to an increase in correlation over time. To gain a better understanding of the process driving activity in Asia one needs to move beyond such a simple correlation analysis. Therefore, we turn to examine the results of the linear dynamic factor model. 


\section{Table 4}

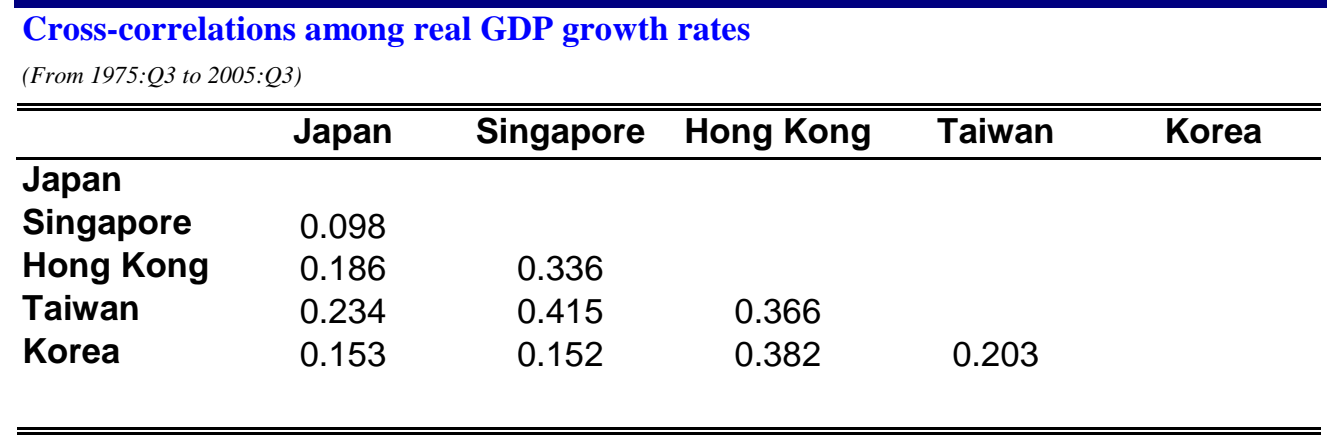

\section{Table 5}

Cross-correlations among real GDP growth rates

(From 1975:Q3 to 1996:Q4)

\begin{tabular}{lccccc}
\hline \hline & Japan & Singapore & Hong Kong & Taiwan & Korea \\
\hline Japan & & & & & \\
Singapore & -0.108 & & & & \\
Hong Kong & 0.033 & 0.117 & & & \\
Taiwan & 0.034 & 0.141 & 0.230 & & \\
Korea & 0.042 & -0.136 & 0.305 & 0.066 &
\end{tabular}

\section{A common dynamic factor model of East Asian growth}

In this section we examine whether and to what extent activity in the Asian region is driven by a joint business cycle. For this purpose, we estimate the most basic version of the factor model in equation 4 with one common factor and no direct spill-over effects between countries, using real GDP growth rates for the Asian countries. The $A$ matrix is diagonal, with diagonal elements $a_{i}, B$ is a vector with individual elements $b_{i}$ and the $D$ matrix is a one-dimensional scalar $d$.

Table 6 presents the parameter estimates for this model using the GDP growth series for all 10 Asian countries for the period 1993:Q2 to 2005:Q3. The idiosyncratic autoregressive coefficient $a_{i}$ is significant only for Korea, indicating that only in the case of this country growth dynamics contain an autoregressive element which is not sufficiently captured by the dynamics of the common factor. The factor loadings $b_{i}$, which measure how the common factor influences each country's growth rates, are statistically significant for most of the Asian countries. The only exceptions are Japan and China, for which the factor loadings take a small positive value - being particularly small in the case of China - but are statistically insignificant. Thus, it seems that "non-Japan non-China Asia” $\left(\mathrm{NJCA}^{12}\right)$ shares a common factor, driving its growth dynamics. This common factor exhibits a considerable degree of persistence as indicated by the high value of $d$. At the same time, the growth dynamics of China and Japan appear to be sufficiently different from that of the rest of the region so that they can not be captured by the common factor.

\footnotetext{
${ }^{12}$ For ease of notation, we denote the eight East Asian countries including Singapore, Hong Kong, Taiwan, South Korea, Thailand, Malaysia, Indonesia and the Philippines as non-Japan non-China Asia (NJCA).
} 


\section{Table 6}

Parameter estimates (Model with one common factor)

(From 1993:Q2 to 2005:Q3; standard errors in brackets)

\begin{tabular}{|c|c|c|c|c|c|c|c|c|c|c|}
\hline & Jap & Chi & Sin & HK & Tai & Kor & Tha & Mal & Ind & Phi \\
\hline$a_{i}$ & $\begin{array}{l}-0.135 \\
(0.138)\end{array}$ & $\begin{array}{l}-0.103 \\
(0.141) \\
\end{array}$ & $\begin{array}{c}0.038 \\
(0.128)\end{array}$ & $\begin{array}{l}-0.006 \\
(0.125) \\
\end{array}$ & $\begin{array}{c}0.124 \\
(0.134)\end{array}$ & $\begin{array}{l}-0.337 \\
(0.112)\end{array}$ & $\begin{array}{l}-0.008 \\
(0.125)\end{array}$ & $\begin{array}{l}-0.021 \\
(0.108)\end{array}$ & $\begin{array}{c}0.061 \\
(0.117)\end{array}$ & $\begin{array}{l}-0.085 \\
(0.127) \\
\end{array}$ \\
\hline$b_{i}$ & $\begin{array}{c}0.220 \\
(0.114)\end{array}$ & $\begin{array}{c}0.051 \\
(0.114)\end{array}$ & $\begin{array}{c}0.442 \\
(0.113)\end{array}$ & $\begin{array}{c}0.495 \\
(0.113)\end{array}$ & $\begin{array}{c}0.294 \\
(0.113)\end{array}$ & $\begin{array}{c}0.759 \\
(0.114)\end{array}$ & $\begin{array}{c}0.494 \\
(0.113)\end{array}$ & $\begin{array}{c}0.675 \\
(0.104)\end{array}$ & $\begin{array}{c}0.551 \\
(0.109)\end{array}$ & $\begin{array}{c}0.492 \\
(0.115)\end{array}$ \\
\hline$\sigma_{i}$ & $\begin{array}{c}0.953 \\
(0.096)\end{array}$ & $\begin{array}{c}0.993 \\
(0.099)\end{array}$ & $\begin{array}{c}0.808 \\
(0.085)\end{array}$ & $\begin{array}{c}0.767 \\
(0.082)\end{array}$ & $\begin{array}{c}0.904 \\
(0.092)\end{array}$ & $\begin{array}{c}0.546 \\
(0.079)\end{array}$ & $\begin{array}{c}0.770 \\
(0.082)\end{array}$ & $\begin{array}{c}0.498 \\
(0.071)\end{array}$ & $\begin{array}{c}0.667 \\
(0.075)\end{array}$ & $\begin{array}{c}0.787 \\
(0.084)\end{array}$ \\
\hline$d$ & $\begin{array}{c}0.629 \\
(0.124)\end{array}$ & & & & & & & & & \\
\hline \multicolumn{11}{|c|}{$Y_{i, t}=a_{i} Y_{i, t-1}+b_{i} Z_{t}+\varepsilon_{i, t}$} \\
\hline
\end{tabular}

The estimated common factor for real GDP growth is plotted in Chart 2. The common factor suggests that the Asian economies experienced two major downturns since 1993: the Asian crisis at the end of 1997 and in 1998 and a less pronounced downturn starting in the early 2000s. Although for the group as a whole, the Asian crisis constitutes, by far, the more important downturn, the more recent downturn appears to have been roughly in line with the Asian crisis in the case of the NICs - Singapore, Hong Kong, Taiwan and South Korea. This is suggested by the common factor for this subgroup, which shows two downturns of approximately equal size (Chart 3).

\section{Chart 2}

Asian countries common factor in real GDP growth (China, Hong Kong, Indonesia, Japan, Korea, Malaysia, Philippines, Singapore, Taiwan, Thailand)

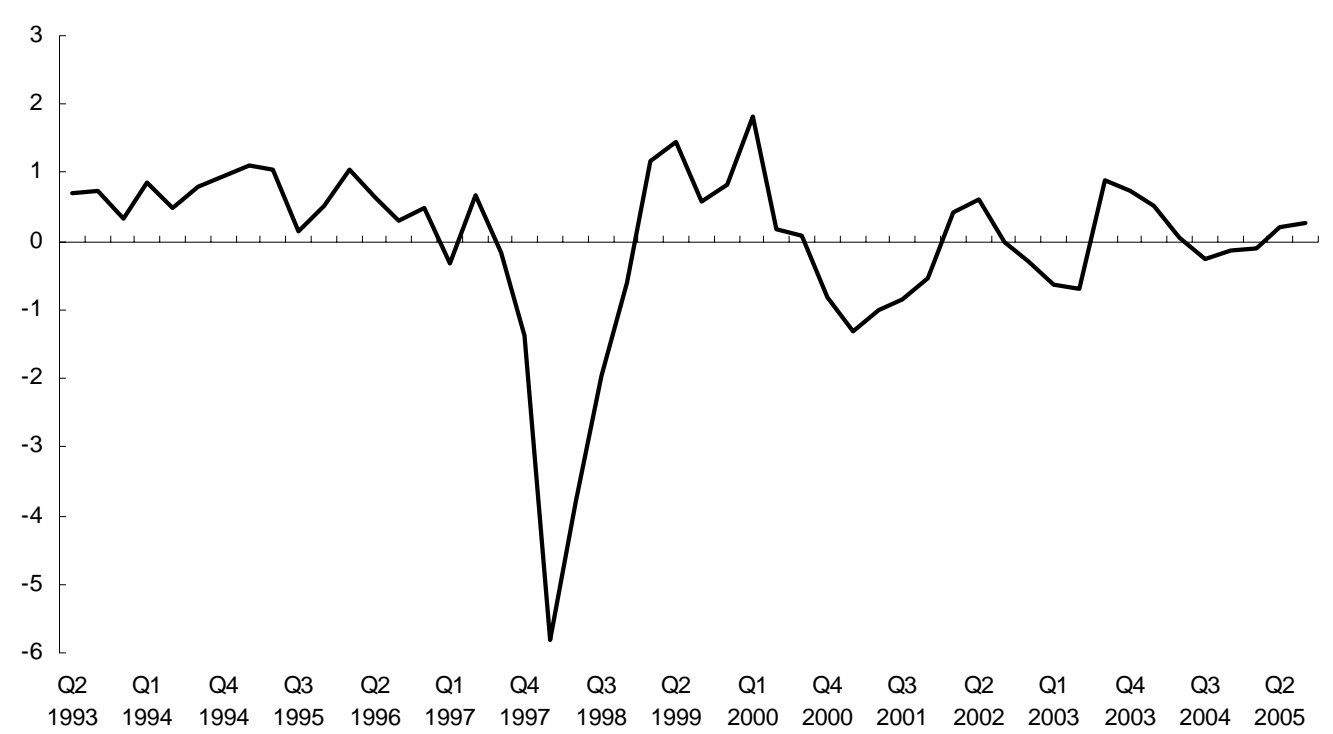




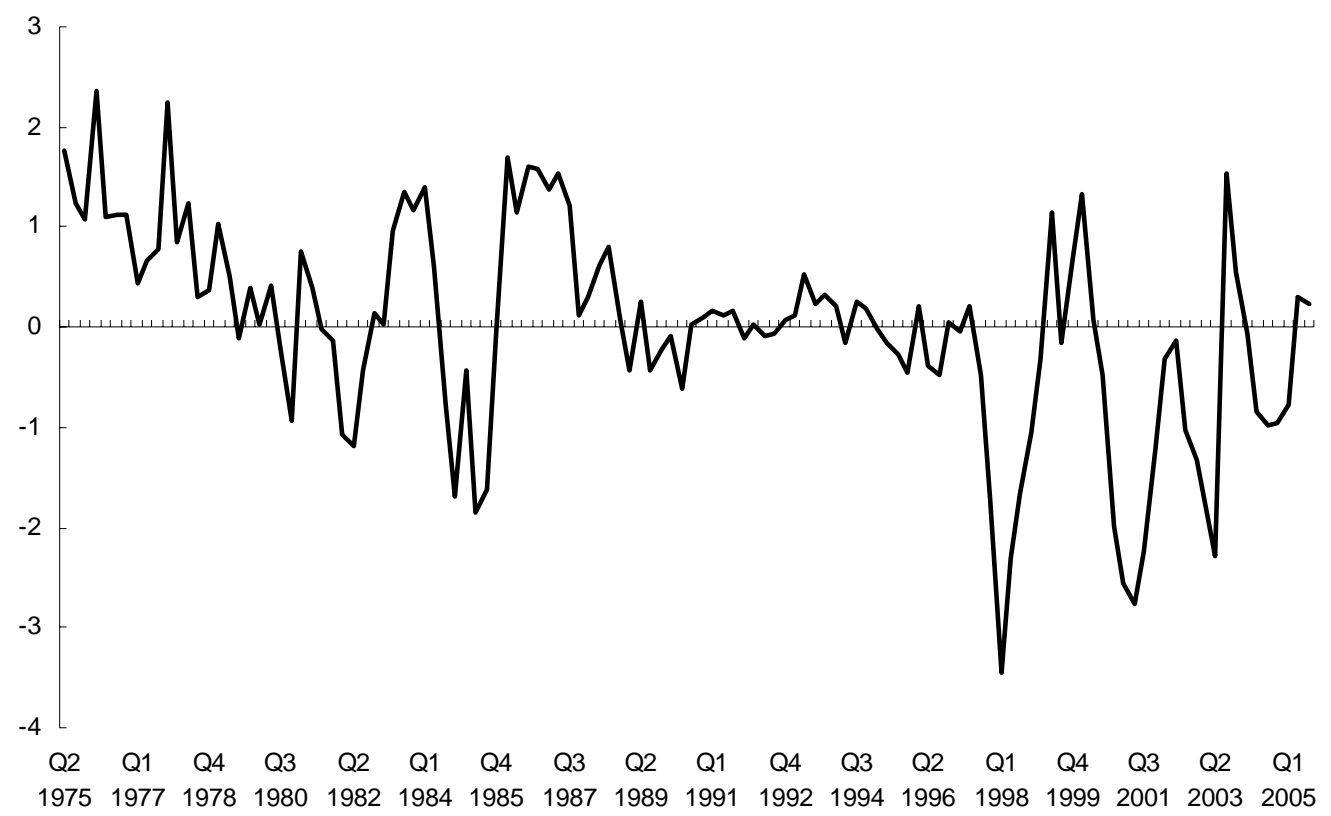

To understand the extent of the co-movement in real GDP growth among the various countries, we derive two different measures of synchronisation. The first is given by the share of the variance of real GDP growth of each country explained by the dynamics of the common factor, which can be derived from the moving average representation of the model. The second is the simple correlation between the GDP growth rate and the common factor. The information contained in these two measures is very similar and they, in general, provide the same ranking of the various countries with respect to the importance of the common factor in explaining their output movements. The former measure is preferable from a theoretical point of view because it takes into account the entire dynamic response of each country's activity growth to shocks to the common factor. However, the latter measure, which ignores such dynamics and concentrates on the contemporaneous co-movement, has some practical advantages. In particular, it can be easily calculated for sub-periods and can therefore provide insights into the evolution of synchronisation over time.

Table 7 demonstrates that the common factor plays a significant role for NJCA, as the share of variance is relatively high for most countries ${ }^{13}$. In particular, the values for Korea and Malaysia are very high. By contrast, the variance of the common factor explains very little of the output variation in the case of Japan and China and the correlation measure is likewise relatively low. This confirms again that Japan and China do not share a common factor with the rest of Asia.

\footnotetext{
${ }^{13}$ The same conclusion is reached when using the correlation measure. But as the ordering of countries with respect to the importance of the common factor is exactly the same as for the share-of-variance measure the results are omitted.
} 


\section{Table 7}

Shares of variance of real GDP growth accounted for by the common factor

(From 1993:Q2 to 2005:Q3)

\begin{tabular}{lcccccccccc}
\hline \hline & Jap & Chi & Sin & HK & Tai & Kor & Tha & Mal & Ind & Phi \\
\hline & & & & & & & & & & \\
$S_{i}$ & 0.070 & 0.004 & 0.342 & 0.406 & 0.170 & 0.675 & 0.403 & 0.747 & 0.550 & 0.368 \\
\hline \hline
\end{tabular}

\section{Chart 4}

Asian NICs - Average correlation between GDP growth and common factor (Hong

Kong, Korea, Singapore, Taiwan)

(Correlation computed over a 2-year moving window)

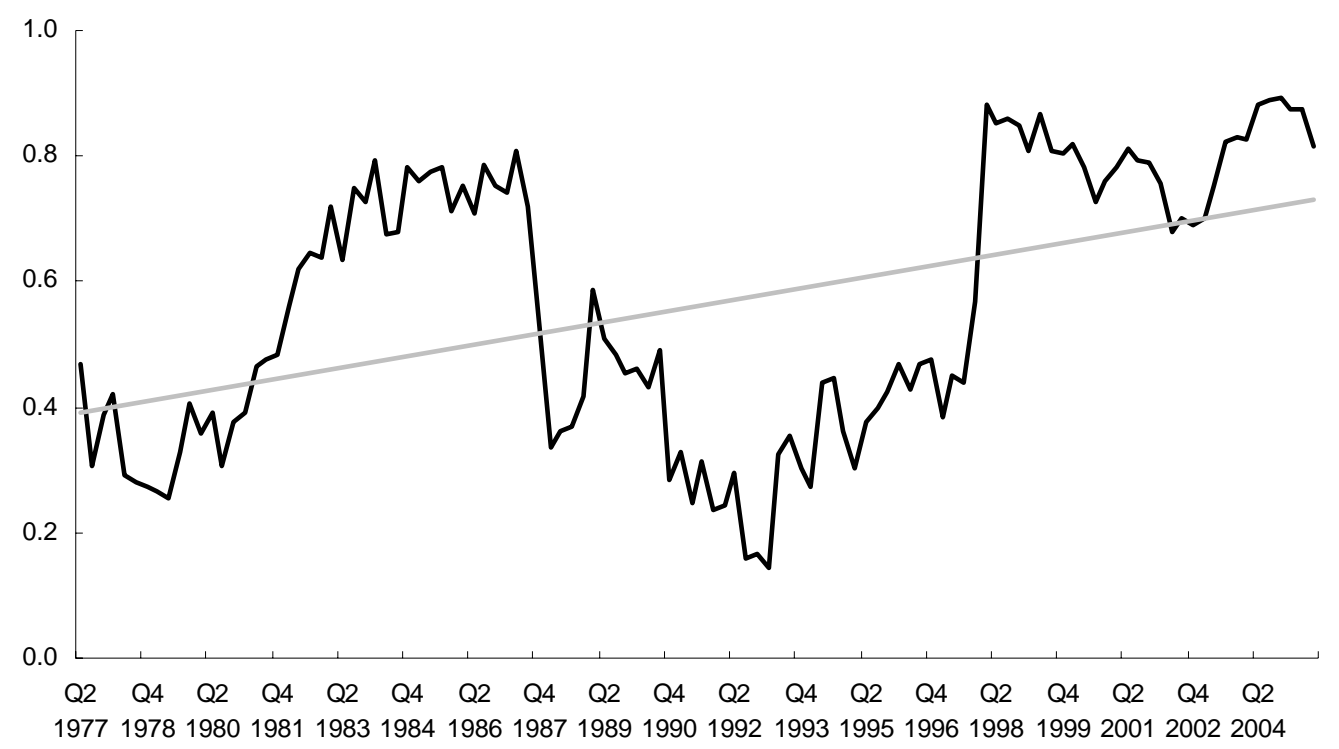

In order to analyse the evolution of synchronisation over time, we calculate a 2-year rolling window correlation between GDP growth and the common factor. Chart 4 shows the average of this correlation for the four NICs. In contrast to the findings of Monfort et al. (2003) for the G7, there is a moderately increasing trend of the synchronisation measure over time. The linear trend, of course, masks the fact that synchronisation appears to go through cycles, with a high-correlation phase in the mid-1980s followed by a low-correlation phase, to be followed again by high correlation in the last decade. As the degree of correlation in the latter period is higher than in the earlier high-correlation period, the overall synchronisation trend is positive. Although the Asian crisis and the ICT bubble burst of 2000-2001 may help to explain the higher correlation in the last decade, it can not account for all of it, as the correlation remains high even after the Asian crisis and excluding 2000 and 2001. Looking at individual country correlation patterns, the increasing trend is particularly pronounced in the case of Singapore, while the trend is virtually flat for Taiwan. The cyclical pattern is most evident at the country level in the case of 
Korea, with Taiwan exhibiting the lowest degree of cyclicality. Turning to the wider country group, a similar increasing trend can be identified since the mid-1990s (see Chart 5). Although the Asian crisis clearly resulted in an increase in overall synchronisation, the subsequent decline in the synchronisation measure is relatively modest and the degree of correlation remained above the pre-crisis level, confirming the finding for the sub-group of NICs. In fact, splitting the sample into NICs and the remaining ASEAN countries reveals that the post-crisis increase in correlation was mainly the result of the increased synchronisation among the NICs, while the correlation of the ASEAN countries declined much more substantially.

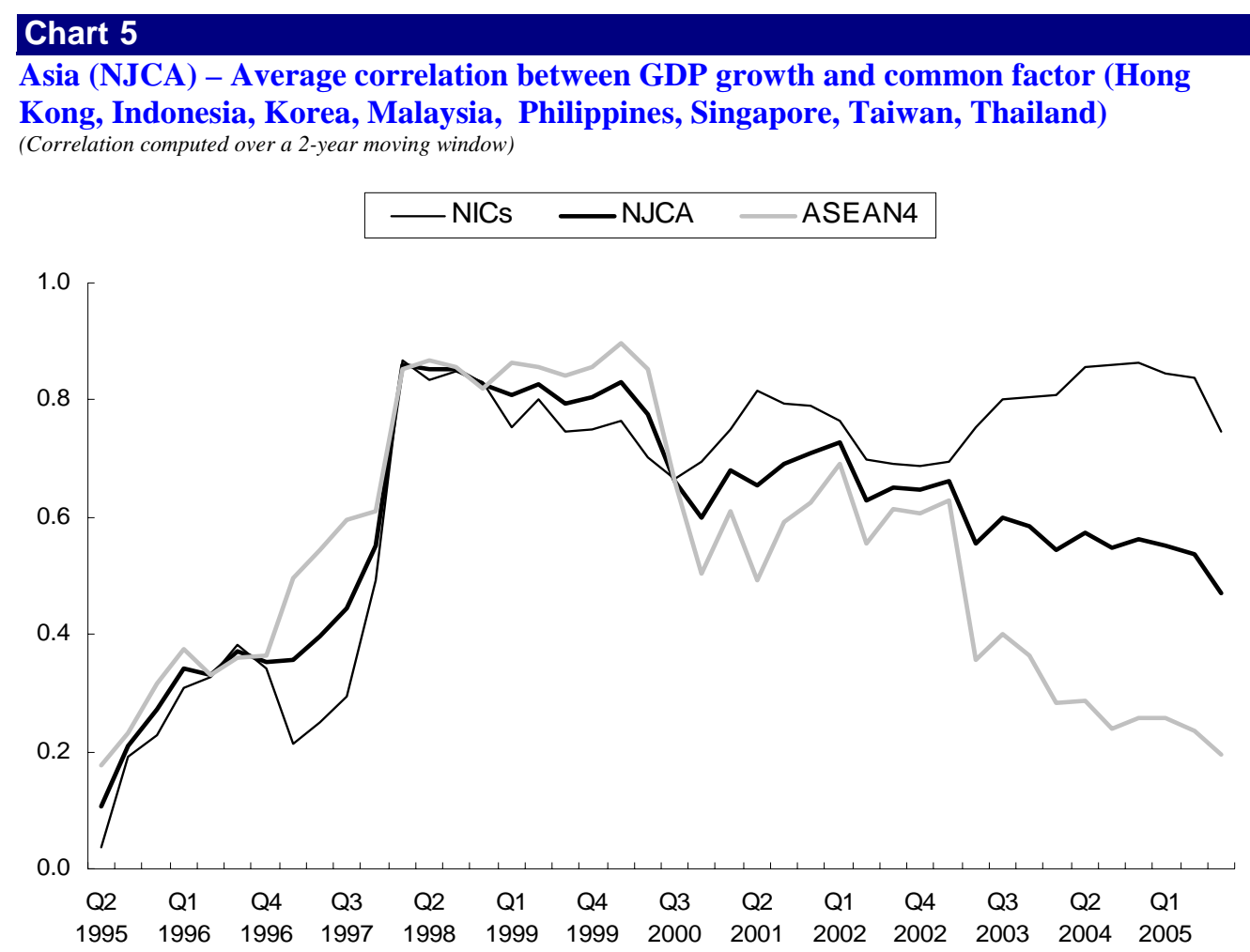

Partly as a robustness check and partly as a first attempt to understand the underlying factors causing the co-movement in the Asian region we also estimated the dynamic factor model for industrial production data. One potential advantage of industrial production is the monthly frequency, which could be useful in disentangling more clearly common shocks from spill-over effects as a source of synchronisation. However, estimating the model with monthly data yields a negative autoregressive coefficient on the common factor, which makes it difficult to interpret the factor as a cyclical phenomenon. ${ }^{14}$ Rather it appears that the monthly industrial production figures are very noisy and volatile. Although this noise seems to contain some common features across countries, we prefer to average out some of the volatility

\footnotetext{
${ }^{14}$ The negative autoregressive coefficient on the common factor is mainly a reflection of the fact that in all countries except for Hong Kong the month-on-month growth rate of industrial production follows an autoregressive process with a negative coefficient on the first lag.
} 
by converting the monthly figures to a quarterly frequency. Using quarterly data we obtain a well-defined specification with a significant positive autoregressive coefficient for the common factor (0.62). Interestingly, this parameter is almost identical to the one on overall GDP, suggesting that either the same process driving GDP also drives industrial production or, alternatively, that the synchronicity of manufacturing activity in Asia is one of the main reasons for the observed co-movement in GDP. On average, the variance explained in the various countries by the common factor is somewhat higher in the case of GDP (37\%) than for industrial production (29\%). Unlike in the case of overall GDP, the common factor proves to be quite important for Japan in the case of industrial production, accounting for almost half of the variance (see Table 8). For China, the common factor remains however relatively insignificant. In general, the relative importance of the common factor for the various countries exhibits some differences between GDP and industrial production, with the correlation between the explained shares of variance being $20 \%$. The countries for which the common factor is the most and least important remain however the same, Malaysia and China respectively.

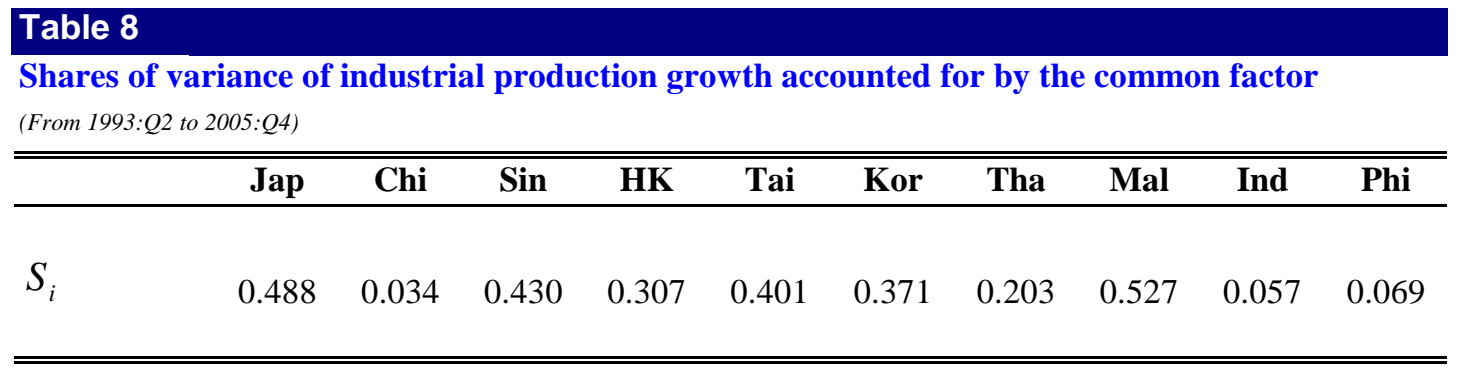

With respect to the evolution of activity synchronisation over time, the industrial production analysis broadly confirms the previous findings for GDP. As a result of the Asian crisis the average correlation with the common factor increased noticeably (see Chart 6). Although the average correlation declines thereafter it remains at first slightly higher than prior to the Asian crisis. Since 2003, the average correlation has exhibited a declining trend, which is somewhat more pronounced than it is for overall GDP. As in the case of GDP, the average correlation for the newly industrialised countries and for the ASEAN countries has been very similar up to 2003, with a noticeable divergence evident thereafter. While the average correlation for the newly industrialised countries remains high, and even increases initially, the correlation for the ASEAN countries declines markedly, reaching levels around zero starting at the end of 2004. The continued high correlation of the NICs and the generally increasing trend of the synchronisation become even more evident when estimating a common factor model for this group separately. 


\section{Chart 6}

Asia (NJCA) - Average correlation between industrial production growth and common factor (Hong Kong, Indonesia, Malaysia, Philippines, Singapore, South Korea, Taiwan, Thailand)

(Correlation computed over a 2-year moving window)

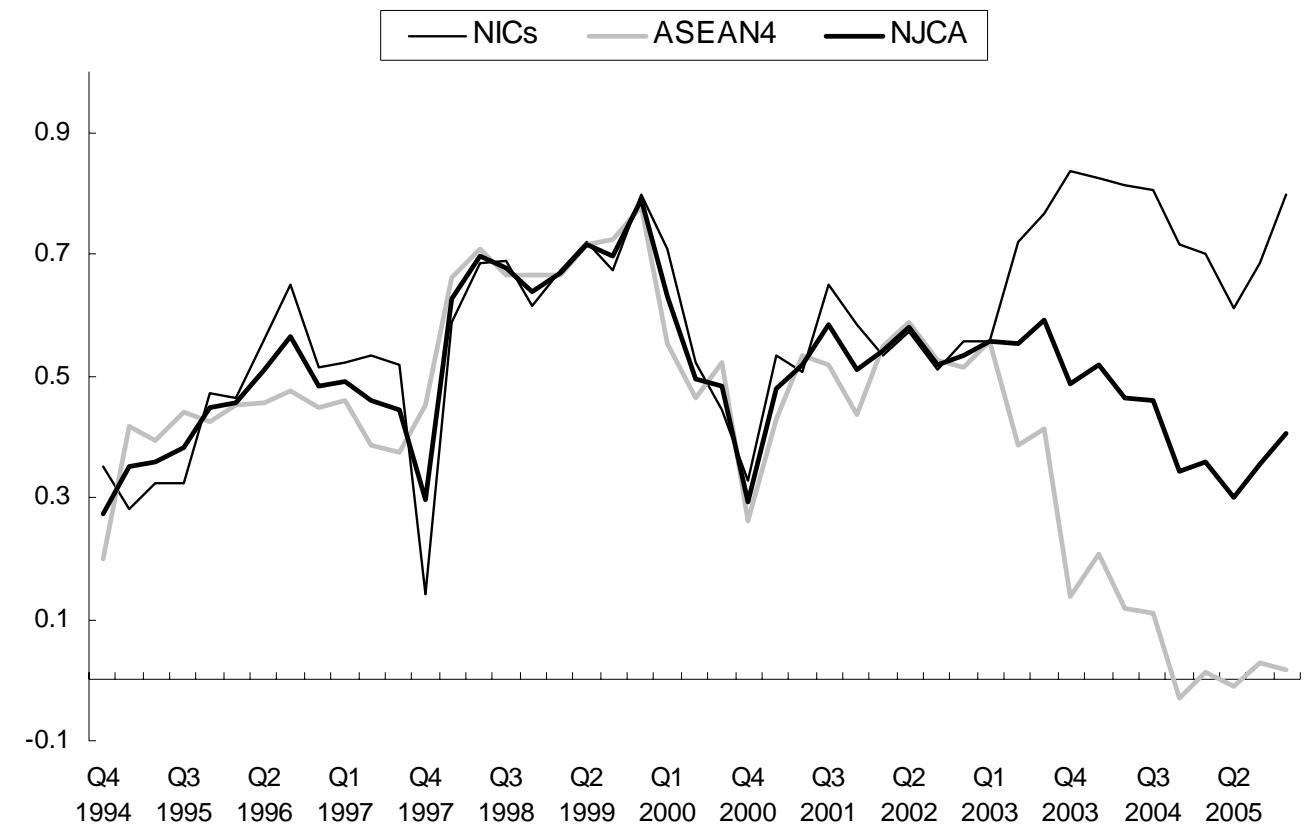

\section{Multiple factors and sub-groups}

To check the robustness of the finding of one common dynamic factor adequately describing the growth dynamics in East Asia, we allow for multiple factors in this section. Such additional factors can take on two basic forms: First, additional factors that are applicable to all countries in the region might be needed, if a single factor is unable to capture the complexity of the overall regional co-movement. This could, for example, be the case if two common shocks affect the countries, each introducing an independent autoregressive component into the countries' activity dynamics. Second, the growth of a subgroup of countries may be characterised by independent dynamics common only to the countries of the sub-group, but not shared with the region at large. 


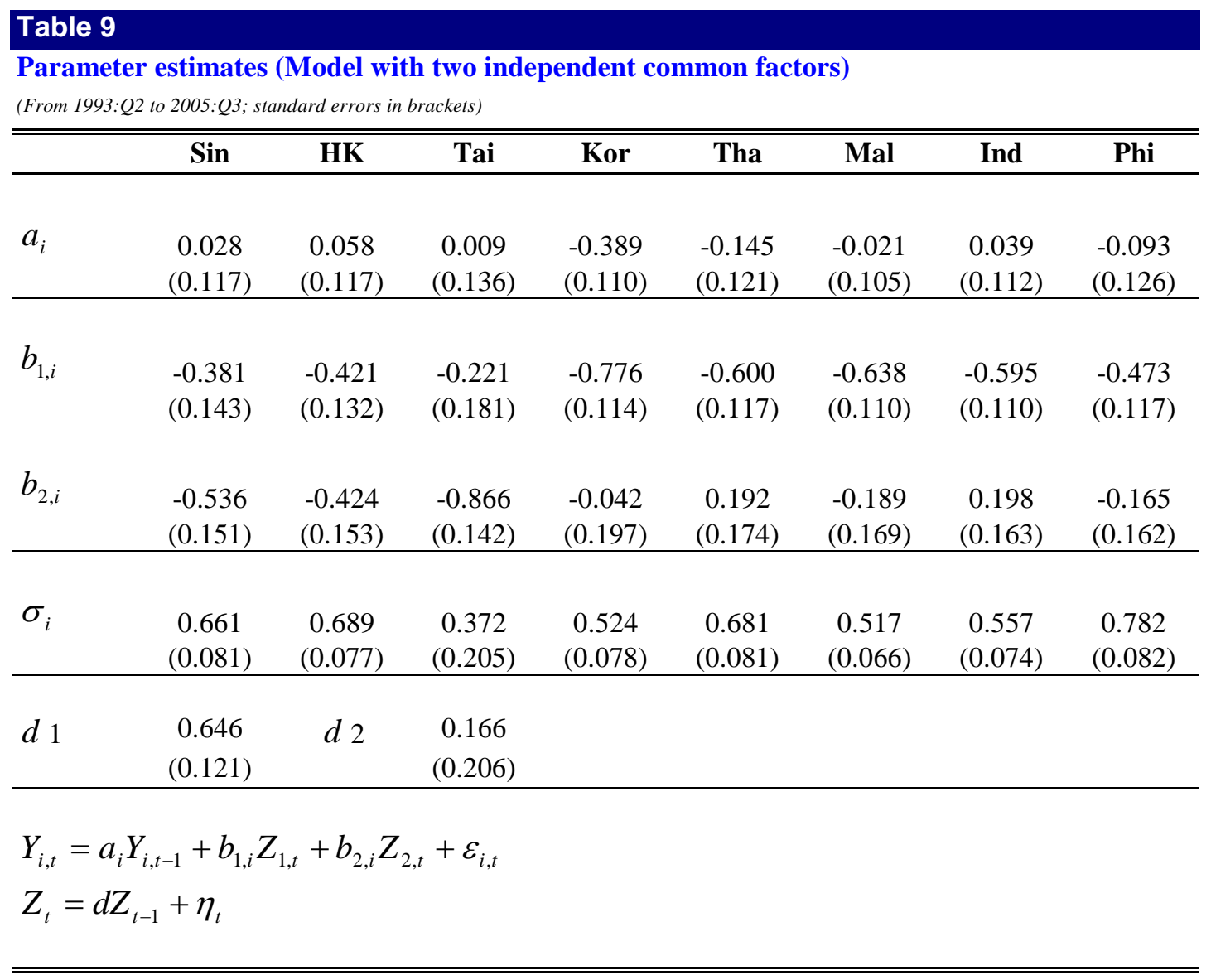

The first case is captured by a modified version of equation 4 , with the $\mathrm{Z}$ process being two-dimensional and the D matrix being diagonal. The estimation results of this model are presented in Table 9. Since Japan and China do not co-move with the rest of Asia we focus our analysis on NJCA. The second common factor, identified by the estimation, has substantially different characteristics than the first. While the first factor has an auto-regressive coefficient $\left(d_{1}\right)$ similar to the one obtained in the one-factor specification, the auto-regressive coefficient of the second factor $\left(d_{2}\right)$ is slightly positive and statistically insignificant. Nonetheless, the second factor proves to be significant for the output dynamics of Singapore, Taiwan and Hong Kong $\left(b_{2, S I N}, b_{2, T A I}, b_{2, H K}\right)$. At the same time, the first common factor is not significant in the case of Taiwan $\left(b_{2, T A I}\right)$ and the coefficients $\left(b_{2, S I N}\right.$ and $\left.b_{2, H K}\right)$ are relatively small for Singapore and Hong Kong. Already in the single-factor model, considering NJCA, the $b_{i}$ coefficients for Taiwan and Singapore are the lowest and the least significant. 


\section{Table 10}

Shares of variance of real GDP growth accounted for by the 2 common factors

(From 1993:Q2 to 2005:Q3)

\begin{tabular}{lcccccccc}
\hline \hline & Sin & HK & Tai & Kor & Tha & Mal & Ind & Phi \\
\hline$S 1_{i}$ & 0.260 & 0.331 & 0.085 & 0.691 & 0.506 & 0.691 & 0.645 & 0.347 \\
$S 2_{i}$ & 0.300 & 0.190 & 0.776 & 0.002 & 0.036 & 0.037 & 0.041 & 0.028 \\
& & & & & & & & \\
\hline \hline
\end{tabular}

The introduction of the second factor underlines the special status of these two countries, possibly including Hong Kong, relative to the other Asian countries. Regarding the share of variance explained by the two factors (Table 10), the share of variance explained by the second factor is higher than the share explained by the first factor only for Taiwan and Singapore. The special status of Taiwan and Singapore in comparison with the other Asian economies was also evidenced during the two most recent downturns. While Taiwan and Singapore were least affected by the Asian crisis, they were the most seriously affected Asian economies during the 2001 recession. ${ }^{15}$ This may be a reflection of the higher concentration of these countries' industries in the high-tech sector.

To test more formally for the existence of some sub-groups among the Asian countries, we consider another specification of the dynamic common factor model, which includes a common factor and two "area” factors. As shown in more detail in section 11, an "area” factor is a factor common only to a subset of countries. Using a likelihood ratio test, we examine whether the introduction of area factors in addition to the common factor increases the overall fit of the model significantly. First, we consider an area factor for Singapore and Taiwan and another one for the rest of NJCA. The log likelihood improves significantly from -478 to -459 and therefore we reject the null hypothesis that "area" factors are not needed to capture Asian growth dynamics. However, if we estimate the model for a longer historical period and therefore only for the NICs it is more difficult to identify a sub-group, such as Singapore and Taiwan, exhibiting common growth dynamics distinct from the rest of the group. Therefore the finding that the business cycles of Singapore and Taiwan co-move separately from the rest of Asia might be largely a result of the last two recessions.

In addition, we tested for the existence of separate NIC and $\operatorname{ASEAN}^{16}$ factors. The log-likelihood improves significantly but less than above (from -478 to -462). Furthermore, Bayoumi and Eichengreen (1994) suggested another classification: a Northeast Asian block (Japan, Korea and Taiwan) and a Southeast Asian block (Hong Kong, Indonesia, Malaysia, Singapore and Thailand). In this case the loglikelihood improves but not significantly (from -486 to -478). Thus, we can not reject in all cases the null hypothesis that "area” factors are not necessary to capture Asian growth dynamics. However, no clearly identifiable and time-invariant sub-groups seem to exist. Although a single common factor may thus not

\footnotetext{
${ }^{15}$ For a more detailed discussion of this issue, see, for example, Yu (2003).

${ }^{16}$ Although Singapore belongs also to ASEAN, we will consider it as part of the NICs in our analysis.
} 
capture all the co-movement within East Asia at all times, it appears to be a reasonable specification for the period as a whole and the subsequent sections therefore focus on this baseline case.

\section{Comparison with some European countries}

Before turning to an analysis of the factors behind Asian synchronisation, it seems useful to gain an additional understanding of the importance of synchronisation within East Asia by comparing it to the degree of synchronisation in another region. We therefore conduct the same analysis for a group of eight countries within the euro area. ${ }^{17}$

As shown in Table 11, the common factor for the euro area countries is significant for all the countries considered - i.e. the $b_{i}$ coefficients are all statistically significant. Similar to the results for the Asian economies, the common factor exhibits a high degree of persistence, with an autoregressive component of almost 0.7. The high share of variance of most countries' real GDP growth explained by the common factor suggests that there is a considerable degree of co-movement between the euro area countries (see Table 12). Greece and Finland appear to be the countries in the sample least synchronised with the common factor.

Comparing Table 12 with Table 7, it seems that the co-movement in NJCA real GDP growth is somewhat stronger than the co-movement of euro area real GDP growth. The average share of variance in the case of the euro area (excluding Greece) is 0.32 for the entire sample period, and 0.27 for the sample period 1993:Q2 to 2005:Q3, which corresponds to the sample period available for the Asian countries. This compares to an average share of variance of 0.46 for the Asian countries (excluding Japan and China). However, it is important to note that the results for East Asia were likely affected by the Asian crisis and the bursting of the ICT bubble. Unfortunately, the pre-crisis sample is too short to allow any meaningful quantification of the magnitude of this effect. Nonetheless, it is possible to conduct a plausibility check by comparing the results for the sub-group of the four newly industrialised countries for which a longer sample is available. For the period 1980:Q2 to 2005:Q3, also used for the European countries, the average share of variance is 0.39 still larger than the European average. This value however drops to 0.27 when the sample ends in 1996:Q4 (for the euro area countries excluding Greece the average for the same period is 0.32). Thus, excluding the Asian crisis and the most recent period it leads to a reduction in the average degree of synchronisation. A similar decline is likely to occur for the East Asian group as a whole. Thus the finding of stronger co-movement may be explained by the Asian crisis and the ICT bubble burst of 2000-2001. However, at least for the NICs the co-movement in output growth appears to be also present in non-recession periods. At the same time, when trying to apply results about the degree of synchronisation to the issue of monetary co-operation in Asia it is important to recognise that a high

\footnotetext{
17 The countries are Belgium, Germany, Spain, Finland, France, Greece, Italy and the Netherlands, with the choice of the countries being determined by data availability. The sample starts in 1980:Q1 (1980:Q2 after differencing the data).
} 
degree of business cycle synchronisation is not a sufficient condition for an optimal currency area, and may not even be a necessary one. ${ }^{18}$

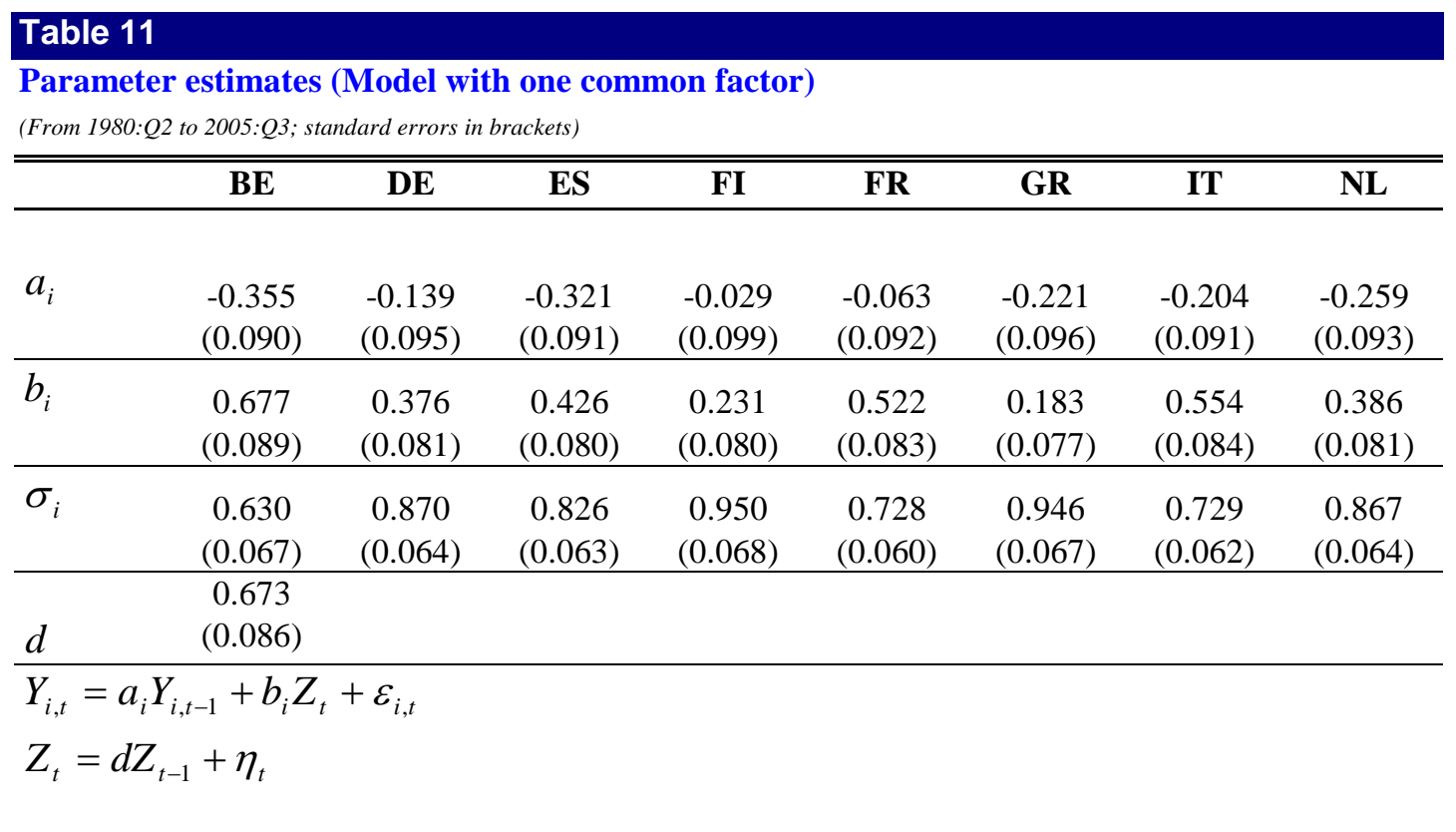

Table 12

Shares of variance of real GDP growth accounted for by the common factor

\begin{tabular}{|c|c|c|c|c|c|c|c|c|}
\hline & BE & DE & ES & FI & FR & GR & IT & NL \\
\hline \multicolumn{9}{|c|}{ (From 1980:Q2 to 2005:Q3) } \\
\hline & $\begin{array}{c}0.565 \\
2005: Q 3)\end{array}$ & 0.221 & 0.239 & 0.094 & 0.463 & 0.048 & 0.445 & 0.203 \\
\hline$S_{i}$ & 0.354 & 0.336 & 0.112 & 0.123 & 0.308 & 0.017 & 0.275 & 0.393 \\
\hline
\end{tabular}

\section{The drivers of co-movement: An analysis of GDP components}

To achieve a better understanding of the factors causing the co-movement between Asian economies, we analyse the synchronisation features of different GDP components in this section. Concretely, three

${ }^{18}$ Bayoumi and Mauro (2001) and Bayoumi, Eichengreen and Mauro (2000) document that on economic criteria (including the importance and composition of intra-regional trade, correlation of aggregate supply shocks across countries, size of shocks and speed of adjustment to them, and degree of similarity of macroeconomics policies) ASEAN seems less suited for a regional currency arrangement than Europe before the Maastricht Treaty, although the difference is not large. However, the authors point out that the essential preconditions are political rather than economic, and Asia comes less close than Europe to meeting those political criteria. 
components of real GDP (exports, private consumption and gross fixed capital formation) are examined using the above dynamic common factor model with one common factor and a diagonal $A$ matrix. ${ }^{19}$

Regarding exports, a common factor, which is significant for all countries' exports, can be identified (see Table 13). ${ }^{20}$ Thus, unlike in the case of the common GDP factor, Japan and China share common dynamics with the rest of Asia with respect to their export performance. Developments in other components thus seem to dominate overall GDP dynamics, breaking the link established through the comovement of exports. This may be a reflection of the fact that Japan and China are relatively closed economies compared to the other Asian economies. In general, the share of variance of export growth explained by the common factor is relatively large (see Table 14), with particularly high values for the three NICs, Hong Kong, Korea and Taiwan. The common export factor exhibits the same degree of persistence as the common GDP factor, as captured by the autoregressive coefficient. This suggests that the synchronisation of exports may play an important role in understanding the overall activity synchronisation in the Asian region.

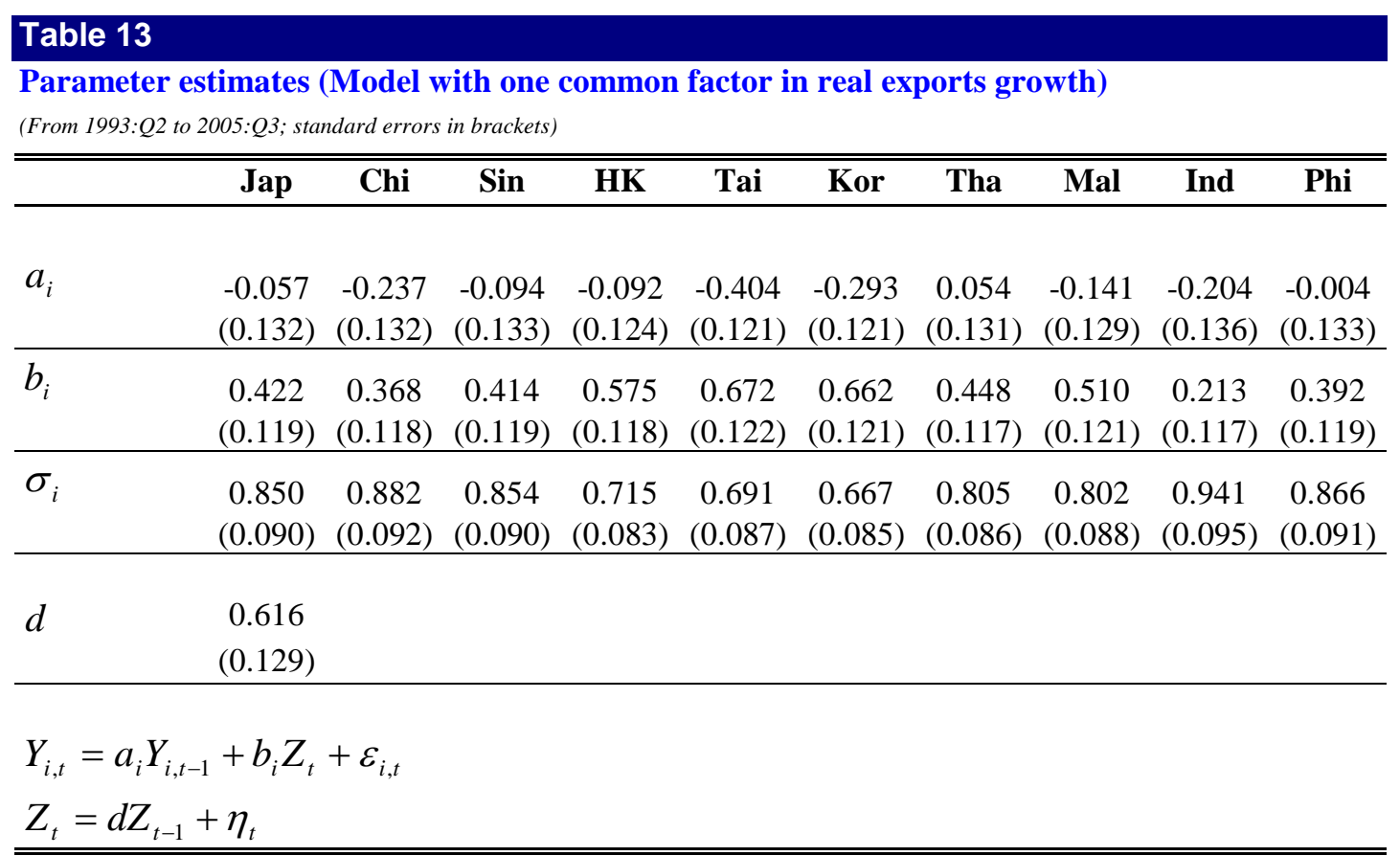

\footnotetext{
${ }^{19}$ We also conduct the analysis for government expenditures. However, the estimation results indicate that there is no common factor for this GDP component, neither for the overall region nor for sub-groups of countries. Thus, public spending appears to be led mainly by domestic motives.

${ }^{20}$ The b coefficient for Indonesia is significant only at the $10 \%$ confidence level.
} 


\section{Table 14}

\begin{tabular}{|c|c|c|c|c|c|c|c|c|c|c|}
\hline & Jap & Chi & Sin & HK & 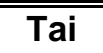 & Kor & Tha & Mal & Ind & Phi \\
\hline$S_{i}$ & 0.270 & 0.173 & 0.252 & 0.482 & 0.478 & 0.524 & 0.348 & 0.354 & 0.060 & 0.247 \\
\hline
\end{tabular}

In open economies with relatively free movement of capital across borders, a country's consumption and investment decisions are not necessarily constrained by its own production. As international financial markets allow for sharing of risk internationally, a large correlation between consumption fluctuations should be expected. We find evidence of co-movement in private consumption and investment, but it appears to be less pronounced than for overall output and shared by only some countries. This is in line with the output/consumption puzzle pointed out by Backus et al. (1992) and documented by several other authors. In contrast to the predictions of most theoretical models, empirically income and output are generally more correlated across countries than consumption (see Table 15). In the case of Japan, Thailand and Indonesia the common consumption factor proves note to be significant. Regarding the share of variance of investment growth accounted for by the common investment factor, no clear pattern emerges (Table 16). For a number of countries, investment co-movement appears to be more pronounced than consumption co-movement, while the reverse is true for other countries. In the case of Japan, Taiwan and Hong Kong the common factor is, in fact, not significant for explaining investment dynamics. This sheds some light on why Japan does not share common output dynamics with the rest of Asia, as both the investment and the consumption common factors do not contribute to the explanation of these demand components. Overall, for the case of Japan, these idiosyncratic dynamics thus appear to outweigh the export-induced synchronisation. ${ }^{21}$

Table 15

Shares of variance of real consumption growth accounted for by the common factor (From 1993:Q2 to 2005:Q3)

\begin{tabular}{lcccccccc}
\hline \hline & Jap & Sin & HK & Kor & Tha & Mal & Ind & Phi \\
\hline$S_{i}$ & & & & & & & & \\
& 0.003 & 0.491 & 0.787 & 0.336 & 0.049 & 0.545 & 0.089 & 0.132 \\
\hline \hline
\end{tabular}

\section{Table 16}

Shares of variance of real investment growth accounted for by the common factor

(From 1993:Q2 to 2005:Q3)

\begin{tabular}{|c|c|c|c|c|c|c|c|c|c|}
\hline & Jap & Sin & HK & Tai & Kor & Tha & Mal & Ind & Phi \\
\hline$S_{i}$ & 0.063 & 0.113 & 0.061 & 0.027 & 0.599 & 0.545 & 0.385 & 0.408 & 0.177 \\
\hline
\end{tabular}

21 Due to data limitations, a similar analysis can not be conducted in the case of China. 
In order to explore heuristically which demand components are particular important in explaining the comovements in real GDP growth, we plot the three common demand component factors together with the common GDP factor for the NICs (see Chart 7-9). ${ }^{22}$ The common export factor exhibits the highest degree of co-movement with the common GDP factor, underlining the important role of exports in shaping the output dynamics in the Asian region. This role of exports is particularly evident in the 1980s and again in the second half of the 1990s. This also helps to explain the observed cyclical behaviour of the correlation between individual countries' GDP growth with the common factor (see Section 5). Interestingly, exports do not seem to be at the centre-stage during the Asian crisis, however they regain their central role in the subsequent downturn. Region-wide investment and consumption dynamics, in general, appear to be less important for regional GDP dynamics. ${ }^{23}$ One important exception is the Asian crisis during which the correlation between the consumption and GDP factor was very high. The investment factor appears to respond with a lag to developments in GDP and other factors, especially during the Asian crisis and the 2001 recession. To the extent that lead-lag structures can be interpreted in a causal way, this suggests that investment dynamics are largely driven by the evolution of exports - and possibly consumption - rather than being a main contributor to the Asian business cycle themselves.

\section{Chart 7}

Asian NICs - common factor in real exports and GDP growth (Hong Kong, Singapore, South Korea, Taiwan)

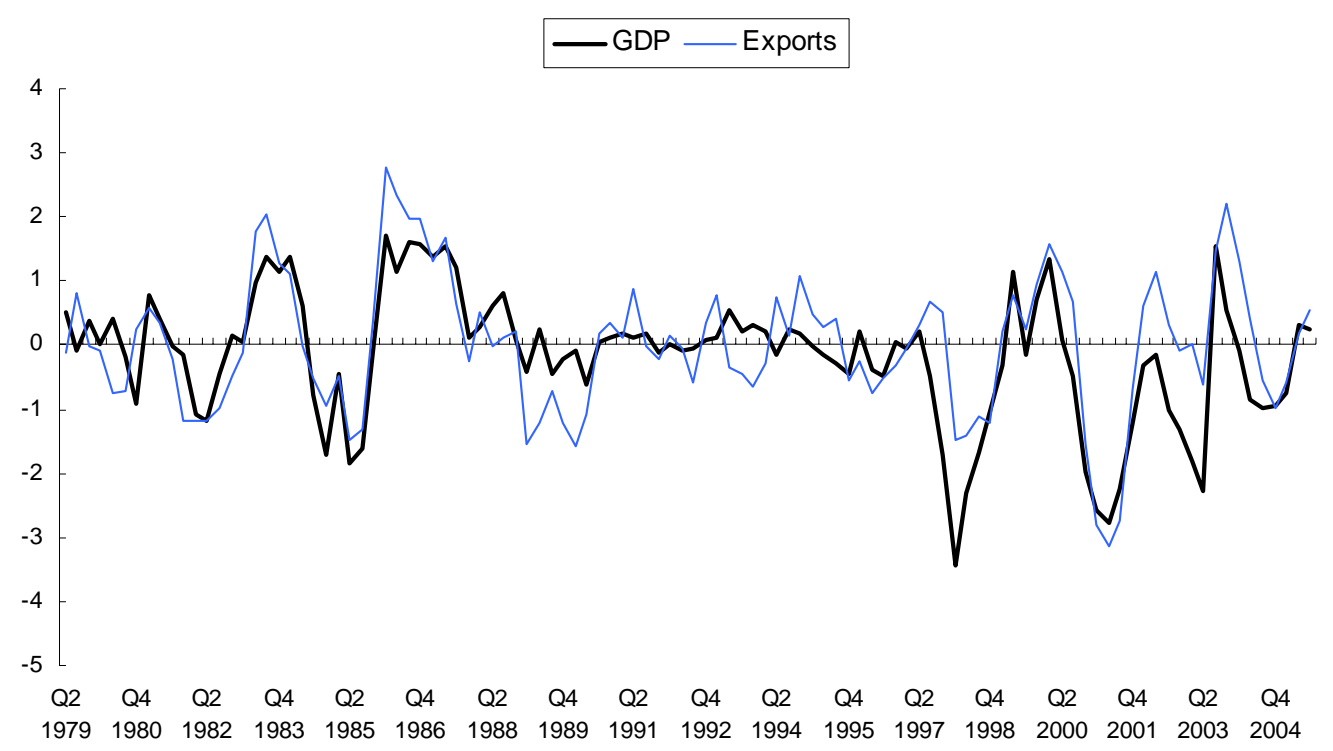

22 Alternatively, we tried to estimate a model with four common factors, one specific to each demand component and one for overall GDP. In addition, we allowed for dynamic links between the different common factors in order to identify their interactions and, in particular, the impact of the three demand components on GDP. Unfortunately, due to the large number of parameters to estimate, the numerical BFGS maximisation algorithm does not converge in that case.

23 The common factor of real consumption growth has been estimated without Taiwan, as Taiwanese consumption does not seem to co-move with that of the other NICs. 


\section{Chart 8}

Asian NICs - common factor in real consumption and GDP growth (Hong Kong,

Singapore, South Korea)

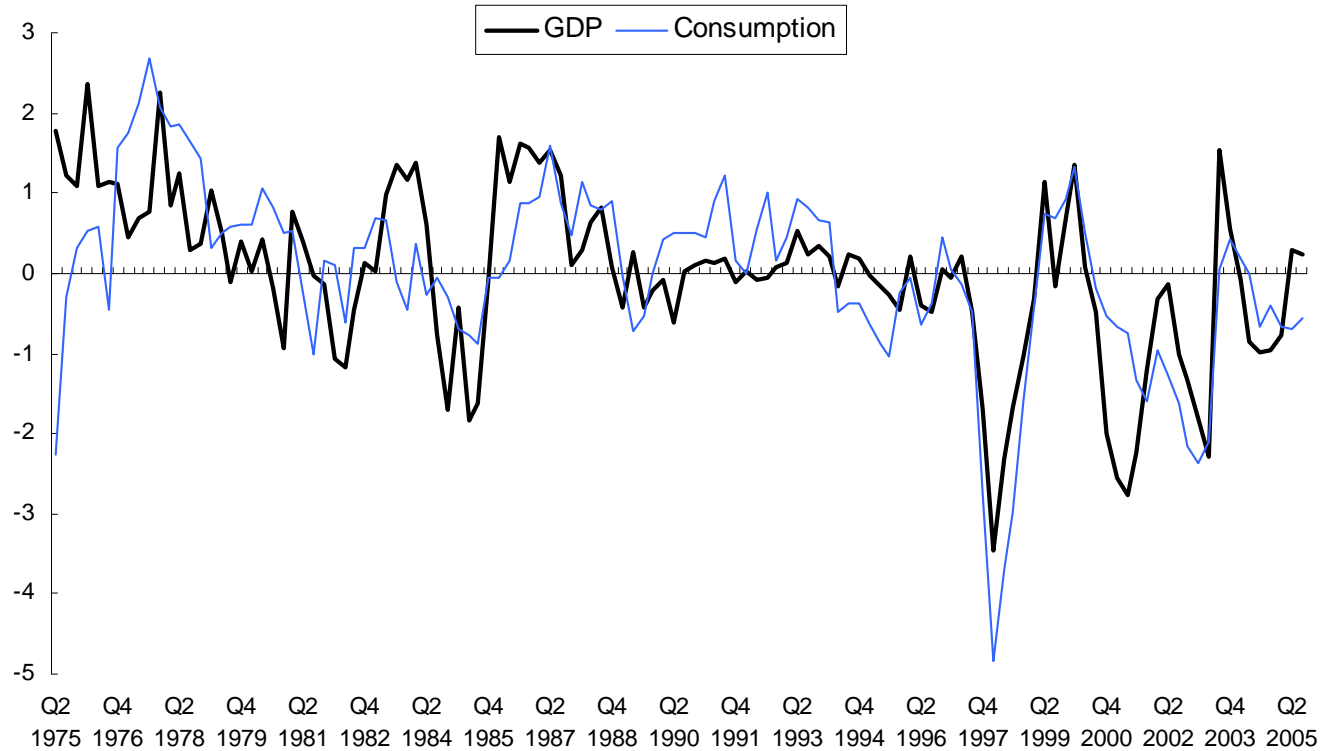

\section{Chart 9}

Asian NICs - common factor in real investment and GDP growth (Hong Kong, Singapore, South Korea, Taiwan)

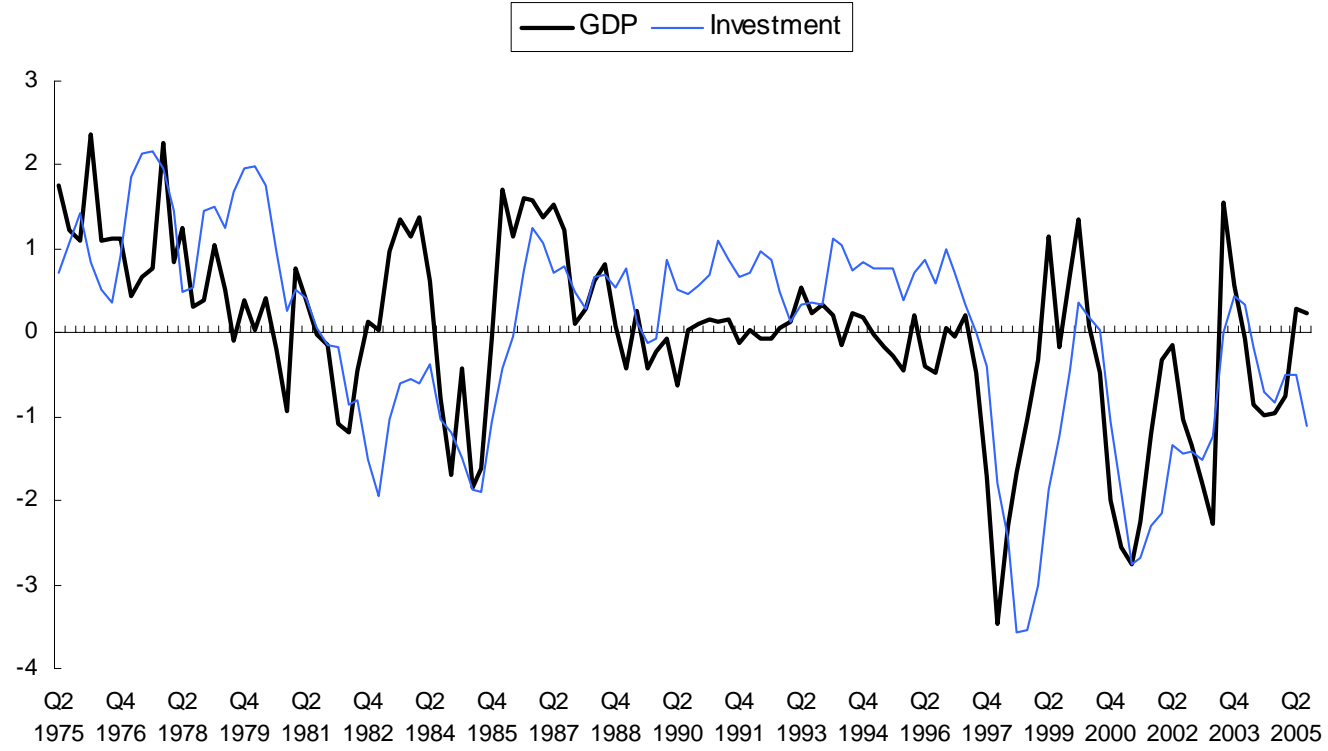

To further investigate the driving forces behind the co-movement in overall GDP, we extend the analysis to include some supply-side components of GDP. In particular, we consider production data for the primary, secondary and tertiary sectors (mining and quarrying, construction, manufacturing, wholesale 
and retail trade, and finance). ${ }^{24}$ Only in the case of manufacturing there is clear evidence for a common factor shared by all seven Asian countries analysed (see Chart 10). ${ }^{25}$ A common factor for a larger subset of countries can also be identified for construction (Indonesia, Malaysia, South Korea and Thailand), for wholesale and retail trade (Malaysia, Taiwan, Thailand, Singapore) and for finance (Malaysia, Singapore, South Korea and Taiwan). Results of the latter analysis might indicate that the financial sectors of the Asian NICs are more integrated and/or more exposed to the same common global shocks. The autoregressive coefficient on the common component is however small and not significant and the comovement in this sector can thus not account for the high degree of synchronisation in overall GDP. No common factor could be found for the mining and quarrying sector. Apart from production in the mining and quarrying sector, the 2-year rolling average correlation between production growth and the common factor shows a slight increasing trend for all sectors. The correlation between the various sectoral common factors and the common factor for overall GDP is highest for manufacturing (0.91), followed by wholesale and retail sales (0.85) and construction (0.83). Thus the results for the supply-side data confirm the evidence for a high degree of co-movement in the manufacturing sector obtained from the industrial production data and are consistent with the high degree of synchronisation in exports.

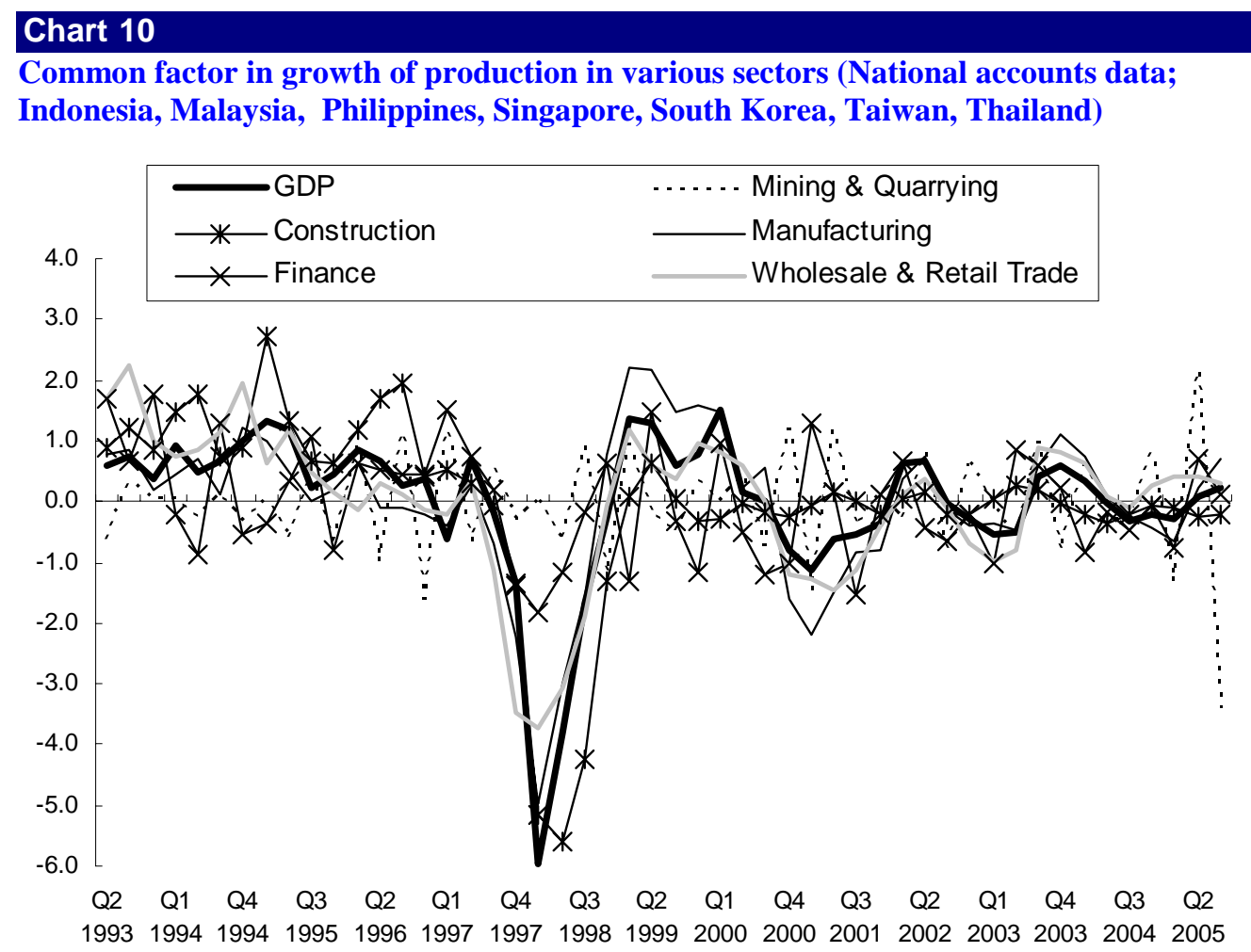

\footnotetext{
${ }^{24}$ In the interest of conciseness, the detailed results are not reported in the paper but can be obtained from the authors upon request.

${ }^{25}$ Due to data availability constraints this analysis focused on the following Asian countries: Singapore, Taiwan, South Korea, Thailand, Malaysia, Singapore and the Philippines.
} 


\section{Structural factors underlying synchronisation I: Intra-regional spill-over effects}

As discussed above, the co-movement, which is captured by the common factor, may reflect either the similar effects of common shocks across countries or, alternatively, the synchronising effect of shocks in one country spilling over to other countries. As the distinction between these two reasons for synchronisation is of crucial importance for policy purposes and for assessing the impact of increased globalisation, we try in this section to extract the part of the co-movement caused by cross-country spillover effects. Concretely, we allow for spill-over effects in the estimated model by relaxing the previous restriction that the $A$ matrix in equation 4 has to be diagonal. By considering the case of a non-diagonal A matrix, the model becomes a mixture of a first-order VAR and a dynamic factor model. The part of any idiosyncratic shock which causes spill-over effects will no longer be categorised as a common shock but will rather be captured by the off-diagonal elements of the $A$ matrix. One major disadvantage of capturing spill-over effects in this way is that it interprets temporal ordering as causal ordering. With forward-looking agents temporal ordering, however, does not necessarily imply causality. A further problem is that this methodology assumes that spill-over effects take one quarter to materialise. Any within-period spill-over effects, which may be significant in the case of a one-quarter period, would not be captured. Thus, at best one can hope to identify part of the spill-over effects.

Given the large amount of coefficients to be estimated in the case of a non-diagonal $A$ matrix, we estimate this extended model only for the NICs for which a longer sample period is available. The estimation results are summarised in Table 17. Only the top half of the off-diagonal elements are statistically significant. All of the coefficients are positive, in line with the general interpretation of crosscountry demand spill-overs. According to the estimates, the output dynamics of Singapore and Hong Kong are affected with a one period lag by developments in Taiwan and Korea, with the spill-over effects stemming from Korea being slightly smaller. In general, the spill-over effect appears to be slightly higher in the case of Hong Kong. In addition, there is some reverse impact of developments in Hong Kong on the Taiwanese economy. The dynamics of the common factor change dramatically in this specification of the model, with the autoregressive coefficient changing to a statistically significant negative number. This contrasts somewhat with the general interpretation of a common factor, as capturing common cyclical developments. ${ }^{26}$ Nonetheless, the common factor remains significant for all four countries, as evidenced by the significant $b_{i}$ coefficients. However, the share of the variance explained by the common factor decreases for all the NICs (Table 18). A decrease in the share of variance would be expected on average, because the part of the co-movement caused by spill-over effects, rather than by common shocks, is modelled separately in the present specification. On average, the share of variance is around $22 \%$ lower than in the specification with a diagonal $A$, suggesting that around one fifth of the co-movement identified

\footnotetext{
${ }^{26}$ In principle, it would be possible that co-movement driven by common shocks introduces relatively short-lived and highfrequency co-movement and that the co-movement which accounts for the more persistent swings in activity is largely due to cross-country spill-over effects. Alternatively, it would be possible that common shocks affect different countries with different lags and are thus picked up as spill-over effects by the dynamic factor model. Possibly reflecting in part such different lags, we believe that it might be particularly difficult to disentangle the two types of factors in the present NIC sample. This is also reflected in the fact that the fit of the model does not improve significantly as a result of the inclusion of spill-over effects.
} 
by the original common factor was due to lagged spill-over effects. However, a likelihood ratio test indicates that the inclusion of cross-country spill-over effects does not improve the fit of the model significantly. Thus, at least for the four NICs, intra-regional spill-over effects do not appear to contribute significantly to the synchronisation of activity within the area, despite the high degree of intra-regional trade.

\section{Table 17}

Parameter estimates (Model with one common factor with VAR 1)

(From 1975:Q2 to 2005:Q3; t statistics in square brackets and standard errors in round brackets)

\begin{tabular}{|c|c|c|c|c|}
\hline & Sin & HK & Tai & Kor \\
\hline & 0.166 & 0.020 & 0.267 & 0.195 \\
\hline \multirow[t]{8}{*}{$A$} & [1.748] & [0.195] & [2.747] & [2.084] \\
\hline & 0.090 & -0.039 & 0.268 & 0.248 \\
\hline & [0.939] & {$[-0.364]$} & [2.731] & [2.591] \\
\hline & -0.044 & 0.178 & 0.359 & 0.172 \\
\hline & {$[-0.475]$} & [1.785] & [3.663] & [1.864] \\
\hline & 0.131 & -0.015 & 0.120 & 0.050 \\
\hline & [1.311] & {$[-0.143]$} & [1.171] & [0.501] \\
\hline & 0.434 & 0.532 & 0.537 & 0.406 \\
\hline \multirow[t]{2}{*}{$b_{i}$} & $(0.100)$ & $(0.105)$ & $(0.103)$ & $(0.104)$ \\
\hline & 0.821 & 0.779 & 0.734 & 0.892 \\
\hline$\sigma_{i}$ & $(0.064)$ & $(0.073)$ & $(0.073)$ & $(0.066)$ \\
\hline$d$ & $\begin{array}{c}-0.446 \\
(0.140)\end{array}$ & & & \\
\hline \multicolumn{5}{|c|}{$Y_{i, t}=A Y_{i, t-1}+b_{i} Z_{t}+\varepsilon_{i, t}$} \\
\hline$Z_{t}$ & & & & \\
\hline
\end{tabular}

\section{Table 18}

Shares of variance of real GDP growth accounted for by the common factor (From 1975:Q2 to 2005:Q3)

\begin{tabular}{lcccc}
\hline \hline & Sin & HK & Tai & Kor \\
\hline$A$ non-diagonal & & & & \\
$S_{i}$ & 0.215 & 0.294 & 0.315 & 0.178 \\
\hline$A$ diagonal & & & & \\
$S_{i}$ & 0.294 & 0.378 & 0.430 & 0.182 \\
\hline \hline
\end{tabular}




\section{Structural factors underlying synchronisation II: Common exogenous shocks}

Rather than trying to model spill-over effects explicitly, one can, of course, try to disentangle the influence of common shocks and spill-over effects by identifying specific common shocks. Probably one of the most important and most easily identifiable common shocks is a change in oil prices, which can have considerable consequences on economic activity. For example, Monfort et al. (2003) find that a significant part of the co-movement in activity in the G7 countries is due to oil price shocks. In addition, there are a number of other variables which are natural candidates as sources of common shocks: Commodity prices more generally, global financing conditions as measured by global equity prices or interest rates, the US monetary policy stance and activity in the industrialised countries. In addition, McKinnon and Schnabl (2003) suggest that the East Asian business cycle might be driven by the fluctuations in the exchange rate of the Japanese yen vis-à-vis the US dollar. As many Asian countries have often tried to maintain relative stability of their currencies with the US dollar any changes in the value of the Japanese yen against the US currency directly translate into changes in the competitiveness of their exports relative to Japanese exports. As a side effect, the improved competitiveness of the Japanese economy implies that Japanese companies have less incentive to use other Asian economies as a cheap production base and FDI flows into these countries will slow as a consequence.

In order to test for the potential explanatory power of these factors for the Asian business cycle we run regressions of the common factors on the different exogenous variables. Due to degrees of freedom constraints each of the explanatory variables is included individually considering contemporaneous values and up to eight lags. The number of lags is reduced in line with a general-to-specific strategy by removing the least significant lag from the regression and re-estimating the equation. This process is repeated until all remaining lags are significant at a minimum level of 5\%. The variables chosen are the price of Brent crude oil, the HWWA commodity price index, the MSCI global equity price index, US 10-year Treasury bond yields, the US federal funds rate, aggregate GDP in the G7 countries and the nominal USD-JPY exchange rate. All variables are expressed in first differences, with the exception of the US interest rates, which are included in levels. The estimation is conducted for the common factor for three different country groupings: all Asian countries, the four newly industrialised countries (entire sample and period beginning 1993) and the ASEAN countries. The estimation results can be found in the Appendix.

Oil prices have some explanatory power for the Asian business cycle, with the adjusted $\mathrm{R}^{2}$ being 0.33 . After a contemporaneous positive effect, regional output is significantly reduced as a result of an oil price increase after seven to eight quarters. The initial positive output effect is likely to reflect the fact that some Asian countries benefit from higher prices as they are net exporters of oil. This is confirmed by the separate regressions for the common factors of Asian sub-groups, which show that the positive output effect is accounted for to a large part by the ASEAN countries. The lagged negative effects, on the other hand, mainly reflect the activity-dampening consequences of an oil price increase for the NICs. Interestingly, this effect is particularly strong if only data from the last decade are considered. This result contrasts to some extent with the finding of Monfort et al. for the G7 countries. Although in both studies oil prices play some role in explaining the common factor, in the case of the G7 countries this influence is 
particularly pronounced at the beginning of the sample period - the 1970s and early 1980s - whereas in the case of the NICs the importance of oil prices increases toward the end of the sample period. This finding may reflect the fact that in the 1970s the NICs had not reached a development stage yet where oil price fluctuations could exert a major influence on activity. While the volatility of oil prices has declined since then, implying by itself a reduced importance of oil prices for economic fluctuations, the dependence of these countries on oil has increased substantially.

The price of commodities more generally also appears to have some impact on Asian growth dynamics. For the region as a whole, the main effect of an increase in commodities prices is a contemporaneous rise in output growth, explaining $17 \%$ of growth dynamics. This positive growth effect is found for both subgroups of countries, with the NICs also experiencing some growth reduction with a three-quarter lag in the shorter sample. Some evidence can be found for a positive connection between growth in Asia and activity in the rest of the world, measured by G7 GDP growth. This positive connection is, however, limited to the NICs whose growth responds positively at lags 0 and 1. For the ASEAN sub-group no significant positive effect can be found. This relatively weak effect of G7 growth is in line with the finding of no significant link between activity in individual East Asian economies and US output growth by McKinnon and Schnabl (2003). The MSCI equity price index has a positive effect only for the NICs with a 1 to 2 quarter lag, explaining around $20 \%$ of the variation. US interest rates, both 10 -year Treasury yields and the federal funds rate, have some positive effect contemporaneously, which is however subsequently reversed. As with the MSCI index, the impact of the long-term yields is limited to the NICs, possibly reflecting their more advanced financial development and greater financial integration into the global economy.

We find also evidence for a link between movements in the USD-JPY exchange rate and activity in Asia, confirming the earlier findings by McKinnon and Schnabl (2003). All significant coefficients have the expected negative sign, indicating that a depreciation of the Japanese yen vis-à-vis the US dollar has a contractionary impact on Asian activity. As one might have expected given the larger export overlap, the NICs are affected most, while the effect on the ASEAN countries is much more muted $\left(\mathrm{R}^{2}=0.07\right)$. In the case of the entire-sample common factor for the NICs lags 0 through 2 and 4 are all significant, with an adjusted $\mathrm{R}^{2}$ of 0.22 . While still an important explanatory factor, in the case of the shorter sample since 1993 the number of significant lags is reduced and the $\mathrm{R}^{2}$ is only around one third of the full sample equivalent. This finding is somewhat surprising as the depreciation of the Japanese yen in the run-up to the Asian crisis is often seen as an important contributor to the crisis. The reduced sensitivity in the post1993 period might perhaps be a reflection of a somewhat weaker orientation towards the US dollar in the post-crisis period, despite some evidence for a relatively fast re-emergence of a de facto dollar standard in Asia after the crisis. 


\section{Structural factors underlying synchronisation III: Inter-regional linkages}

In this section we analyse the extent to which inter-regional linkages may account for East Asian synchronisation. In particular, we estimate to what extent developments in North America and Europe contribute to the dynamics of the East Asian common factor. To that end, we estimate common factors for these two additional regions in a framework that permits lagged interactions between the various regional factors. Concretely, following Monfort et al. (2003), we extend the model by introducing dynamic factors which are common only to a sub-set of series. In the case of $n$ areas, with each area $i$ containing $k_{i}$ series, we have the following notation: $Y_{i, t}^{j}$ where $j=1, \ldots, K_{i}$ indexes the series of the $i^{\text {th }}$ area. Let $N_{i, t}$ be a factor common to all the series in area $i$, which can be thought of as an area specific common factor. In this case, the model becomes:

$$
\begin{aligned}
& Y_{i, t}^{j}=a_{i}^{j} Y_{i, t-1}^{j}+c_{i}^{j} N_{i, t}+\varepsilon_{i, t}^{j} \\
& N_{i, t}=D N_{i, t-1}+\eta_{i, t}
\end{aligned}
$$

In the basic version of the model, the D matrix is diagonal. We are, however, especially interested in the interactions between different area factors and therefore we allow the $\mathrm{D}$ matrix to be non-diagonal. Similar to the case of a non-diagonal A matrix in Section 9, we can study the lagged impact of developments in one area's factor on other area factors. Of course, the same caveat regarding the interpretation of temporal ordering as causal ordering applies in this case.

The composition of the three areas analysed is as follows: the East Asia area consists of the NICs, the North America area of the US and Canada and the Continental Europe area comprises France, Germany and Italy. ${ }^{27}$ The results are shown in Table 19. The regional common factors are significant for all countries in their respective area, as indicated by the $c$ coefficients. Furthermore, the area factors are all characterised by a high degree of persistence, as indicated by the diagonal elements of the D matrix. The North American factor exhibits the highest persistence, while the European factor is the least persistent one.

\footnotetext{
${ }^{27}$ In an initial step, we test whether the addition of three factors corresponding to the above areas significantly improves upon a model that merely assumes that all countries share one common "global" factor. As in Section 8, we conduct a likelihood ratio test for the exclusion of the three area factors. The log-likelihood of the model with the area factors is -1420 compared with -1465 for the case where only the global factor is included in the model. Therefore, we reject the null hypothesis that one global factor is sufficient to capture the growth dynamics of these three regions. As the additional global factor in the specification with three area factors is close to white noise and not significant for explaining most countries' growth dynamics, we omit it from the model specification and focus only on the three area factors.
} 
Parameter estimates (Model with three area factors, NIC/North America/Europe)

(From 1975:Q2 to 2005:Q3; standard errors in brackets)

\begin{tabular}{|c|c|c|c|c|c|c|c|c|c|}
\hline & TSin & 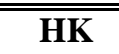 & Tai & Kor & USA & CAN & 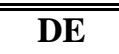 & $\overline{~ F R ~}$ & IT \\
\hline$a^{j}{ }_{i}$ & $\begin{array}{c}0.123 \\
(0.090)\end{array}$ & $\begin{array}{c}-0.102 \\
(0.092)\end{array}$ & $\begin{array}{c}-0.049 \\
(0.105)\end{array}$ & $\begin{array}{c}-0.130 \\
(0.089)\end{array}$ & $\begin{array}{c}-0.097 \\
(0.115)\end{array}$ & $\begin{array}{c}0.178 \\
(0.112) \\
\end{array}$ & $\begin{array}{c}-0.271 \\
(0.087)\end{array}$ & $\begin{array}{c}-0.090 \\
(0.095)\end{array}$ & $\begin{array}{c}-0.033 \\
(0.104)\end{array}$ \\
\hline$C^{j}{ }_{i}$ & $\begin{array}{c}0.361 \\
(0.126)\end{array}$ & $\begin{array}{c}0.445 \\
(0.096)\end{array}$ & $\begin{array}{c}0.570 \\
(0.091)\end{array}$ & $\begin{array}{c}0.325 \\
(0.115)\end{array}$ & $\begin{array}{c}0.511 \\
(0.116)\end{array}$ & $\begin{array}{c}0.448 \\
(0.102)\end{array}$ & $\begin{array}{c}0.328 \\
(0.123)\end{array}$ & $\begin{array}{c}0.458 \\
(0.107)\end{array}$ & $\begin{array}{c}0.491 \\
(0.107)\end{array}$ \\
\hline$\sigma^{j}{ }_{i}$ & $\begin{array}{r}0.855 \\
(0.062) \\
\end{array}$ & $\begin{array}{c}0.828 \\
(0.066) \\
\end{array}$ & $\begin{array}{c}0.686 \\
(0.080) \\
\end{array}$ & $\begin{array}{c}0.913 \\
(0.063) \\
\end{array}$ & $\begin{array}{c}0.712 \\
(0.089) \\
\end{array}$ & $\begin{array}{c}0.654 \\
(0.078) \\
\end{array}$ & $\begin{array}{c}0.870 \\
(0.061)\end{array}$ & $\begin{array}{c}0.737 \\
(0.067) \\
\end{array}$ & $\begin{array}{c}0.665 \\
(0.074) \\
\end{array}$ \\
\hline$d_{1,1}$ & $\begin{array}{c}0.604 \\
(0.126)\end{array}$ & $d_{1,2}$ & $\begin{array}{c}0.138 \\
(0.096)\end{array}$ & $d_{1,3}$ & $\begin{array}{l}-0.060 \\
(0.091)\end{array}$ & & & & \\
\hline$d_{2,1}$ & $\begin{array}{c}0.180 \\
(0.115)\end{array}$ & $d_{2,2}$ & $\begin{array}{c}0.704 \\
(0.116)\end{array}$ & $d_{2,3}$ & $\begin{array}{l}-0.169 \\
(0.102)\end{array}$ & & & & \\
\hline$d_{3,1}$ & $\begin{array}{r}0.284 \\
(0.123)\end{array}$ & $d_{3,2}$ & $\begin{array}{c}0.249 \\
(0.107)\end{array}$ & $d_{3,3}$ & $\begin{array}{c}0.524 \\
(0.107)\end{array}$ & & & & \\
\hline
\end{tabular}

$$
\begin{aligned}
& Y_{i, t}^{j}=a_{i}^{j} Y_{i, t-1}^{j}+c_{i}^{j} N_{i, t}+\varepsilon_{i, t}^{j} \\
& N_{i, t}=D N_{i, t-1}+\eta_{i, t}
\end{aligned}
$$

Regarding the interactions between different areas, the East Asian factor increases with a one-quarter lag after an increase of the North American factor $\left(d_{1,2}>0\right)$. In contrast, the East Asian factor reacts negatively to an increase in the Continental European factor $\left(d_{1,3}<0\right)$. These effects are, however, not significant at conventional levels. Similarly, the North American factor is also not significantly affected by any of the other area factors. In contrast, the European factor is significantly affected by the two other area factors, with the effect from the East Asian factor being particularly pronounced, i.e. the parameter $d_{3,1}$ is rather large and statistically significant. Moreover, in line with the findings of Monfort et al. (2003), the North American factor has a significant lagged impact on the Continental European factor $\left(d_{3.2}\right.$ parameter). ${ }^{28}$ In this context, it is again important to note the fact that the Asian factor appears to have a somewhat stronger impact on the European and North American factors than the other way around may not necessarily imply "true” causality. First of all, any within period spill-over effects would not be picked up in the regional interaction terms. Second, to the extent that changes in economic activity are foreseen, the observed temporal ordering may merely reflect the fact that Asian producers adjust activity in a forwardlooking manner to likely developments in their major export markets. Thus, the estimated positive effect of the East Asian factor on the European and the North American factors, even though the latter is not

\footnotetext{
${ }^{28}$ Selover (2003) also finds that the US does not have any significant impact on Korea. He attributes this to the fact that Korean exports may be relatively insensitive to US business cycle fluctuations. First, initially many of the export goods were low-cost and low-income-elasticity goods, such as textiles and apparel. Second, in the case of Korea many of the US exports actually went to the US military stationed in Korea. Such "exports" would, of course, be relatively immune to business cycle fluctuations in the US.
} 
significant, may reflect causation actually running in the opposite direction, highlighting the dependence of the East Asian region on developments in Europe and to a lesser extent the United States.

In order to illustrate to what extent cross-area spill-over effects have contributed to the common fluctuations in East Asia, we contrast the East Asian factor with a hypothetical factor, where all cross-area interactions are eliminated. This hypothetical factor thus tries to capture East Asia's economic evolution in the case of complete regional autonomy. As shown in Chart 11, the East Asia factor has not been affected very much by developments in the other areas in the most recent period. A more noticeable effect can, however, be seen during the first half of the 1990s. While the East Asian region in hypothetical autonomy would have seen a marked growth deceleration over the period, the interactions with the other two groups has, in fact, contributed to a stabilisation of growth, subtracting some growth at the beginning of the period and adding some toward the end.

As the structure of the economic interrelationship is likely to have changed significantly over the entire sample period we re-estimate the model for the sub-sample starting in 1990:Q1 (see Chart 12). The findings for the first half of the 1990s are confirmed by this re-estimation. Likewise, the Asian crisis continues to be an event specific to the Asian region with little contribution from the other regions. An important difference emerges, however, with respect to the 2000/2001 downturn, which now appears to be much more negatively influenced by developments outside the Asian region.

\section{Chart 11}

Eastern-Asia factor (with and without the contribution of Continental European and North-America specific innovations)

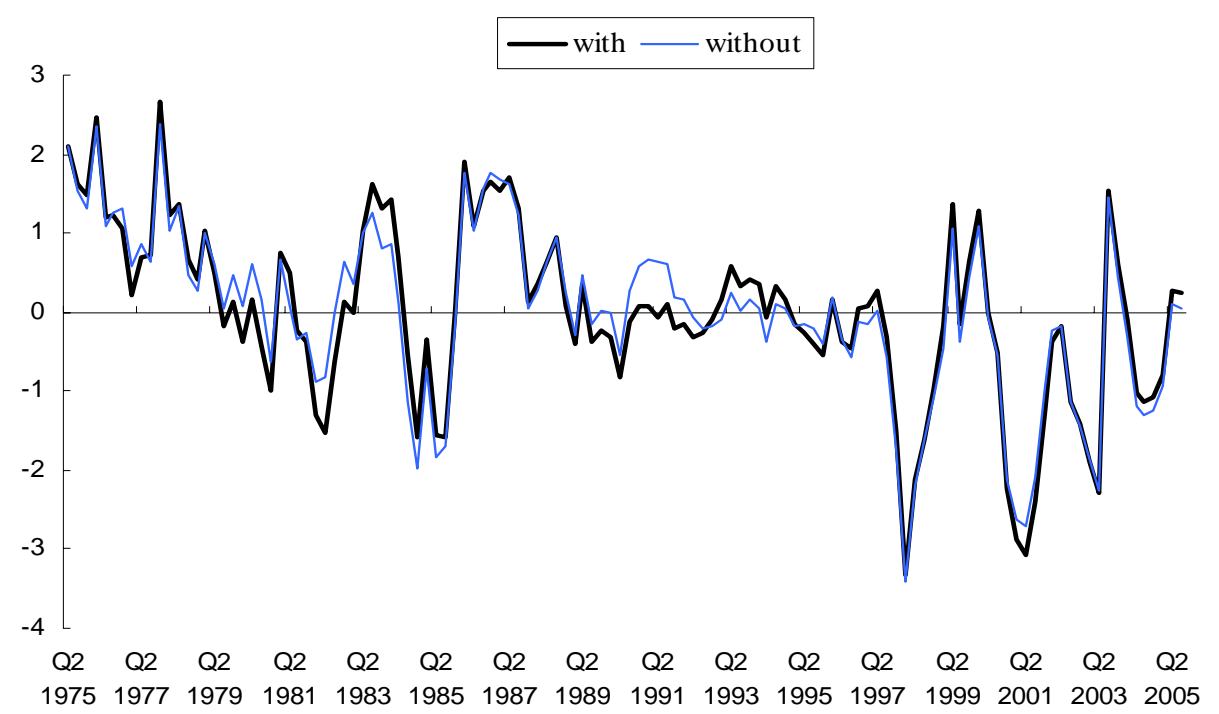




\section{Chart 12}

Eastern-Asia factor (with and without the contribution of Continental European and North-America specific innovations)

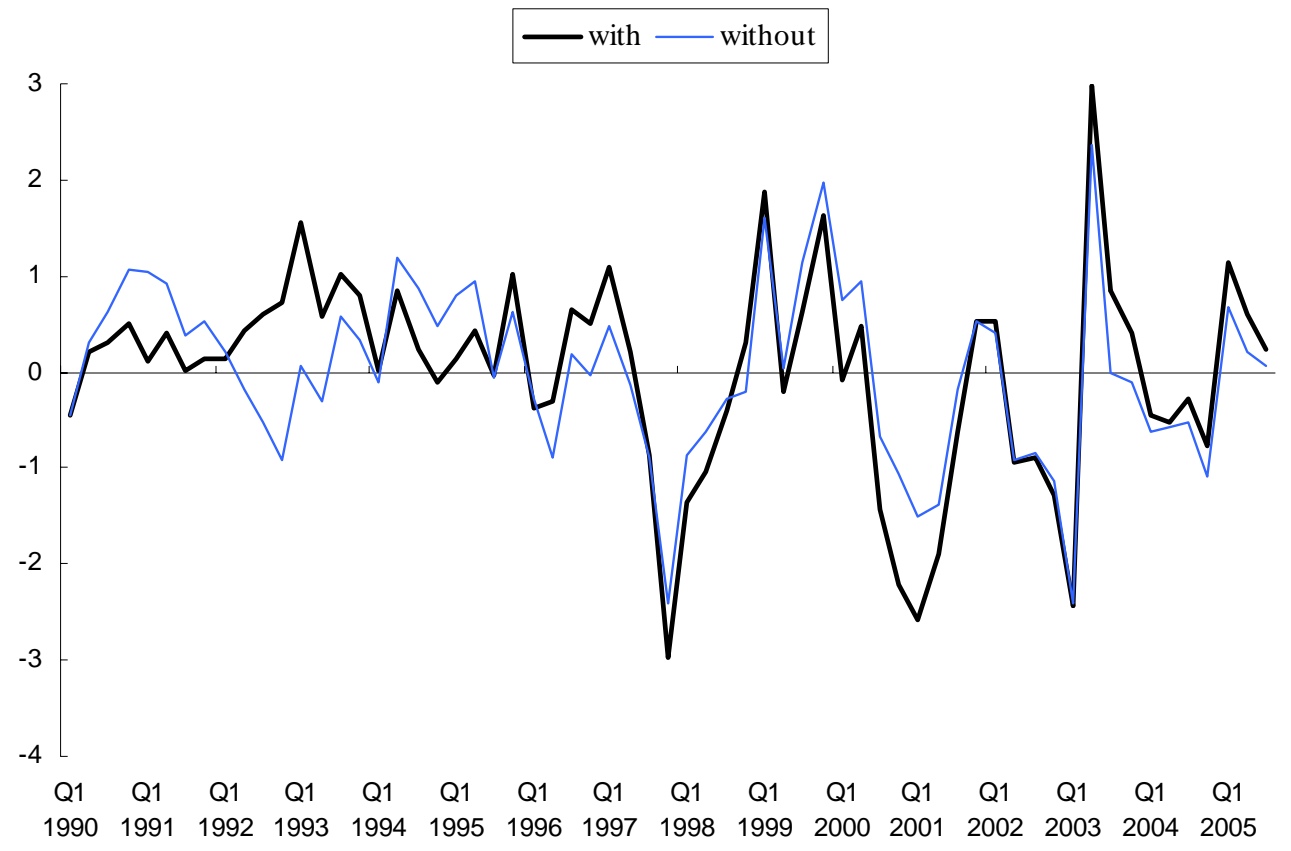

A direct comparison of the East Asian factor with the other two regional factors sheds some light on the estimation results regarding cross-regional spill-over effects (see Charts 13 and 14). While the East Asian factor and the North American factor appear to be synchronised in those cases where similar patterns emerge in the two regions, the European factor appears to lag developments in the Asian factor slightly.

\section{Chart 13}

Continental European and Eastern-Asia common factor in real GDP growth

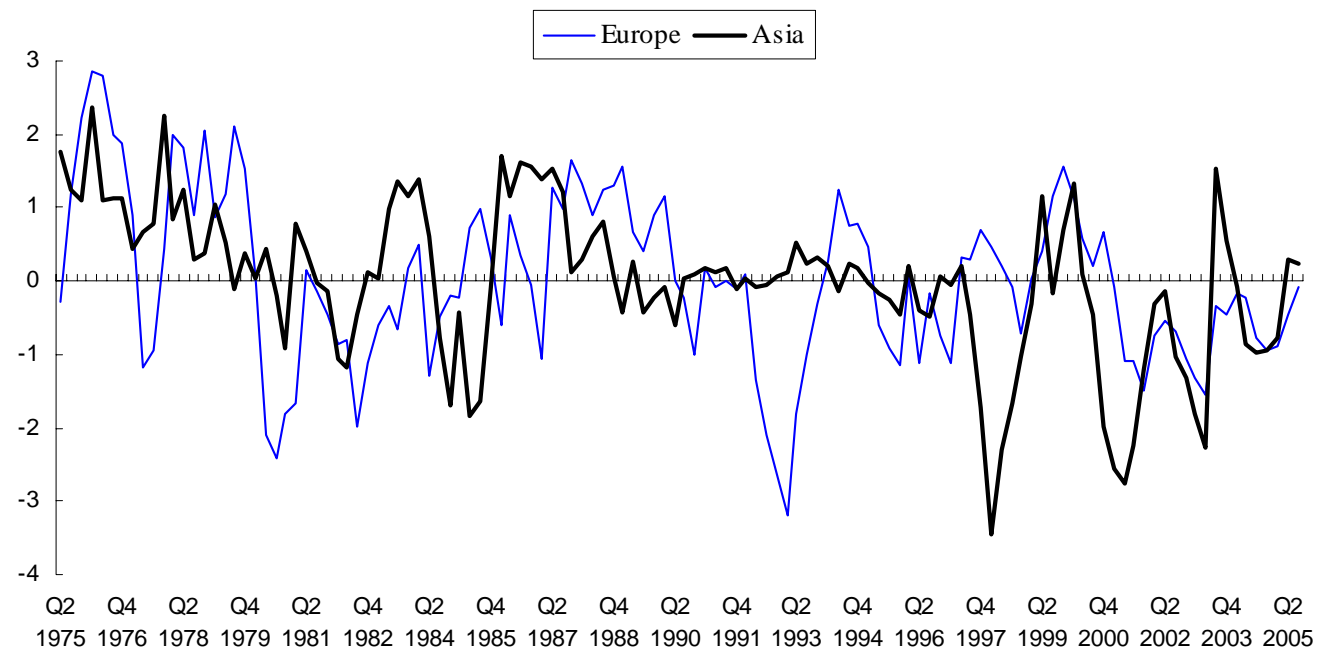




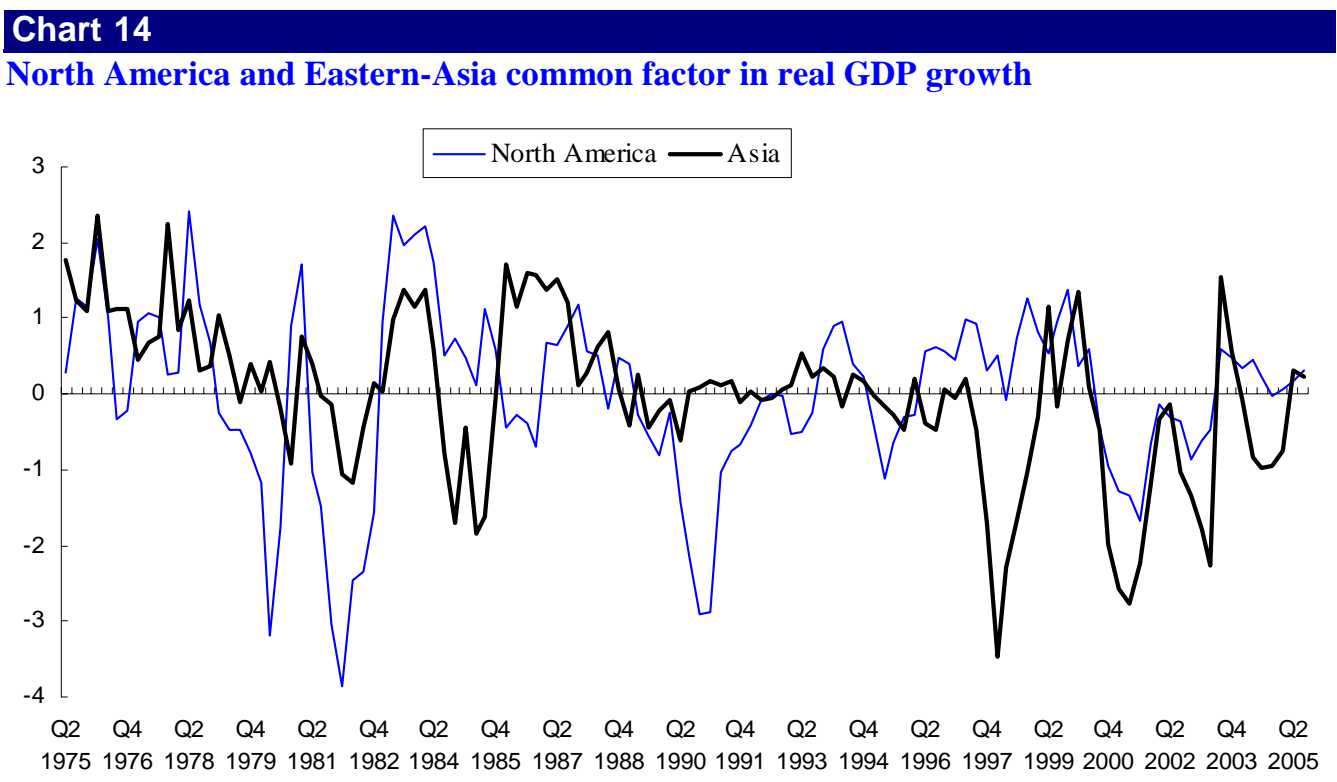

Finally, we estimate the model also for the ASEAN countries. However, given the high number of coefficients to estimate we could not run the model using three area factors, rather we included only two area factors. The results show that between the North American and the ASEAN factor there are no significant spillovers and therefore the two series, with and without foreign innovations, are almost identical and hence omitted. In contrast, the Continental European factor also appears to be affected by the ASEAN specific factor. This is particularly evident during the Asian crisis in 1997/1998.

\section{Conclusion}

The nature of East Asian integration and its impact on the interaction among East Asian countries and between East Asia and other regions has received considerable attention in policy discussions and academic work. In this paper we attempt to provide additional insights into these issues by analysing the nature and degree of synchronisation within Asia and its underlying causes. For that purpose, a dynamic factor model was estimated, using an extended specification in order to capture cross-country and crossarea spill-over effects.

The main findings of the study are as follows: Most East Asian countries share significant common growth dynamics. The exceptions are Japan and China, which appear to be somewhat detached from developments elsewhere in the region. While the Asian crisis has clearly been the most serious recession for the region as a whole, for the NICs (Hong Kong, Korea, Singapore, Taiwan) the more recent downturn in 2000/2001 appears to have been almost equally severe. Over time, the synchronisation of growth dynamics in Asia has increased somewhat, especially for the NICs. To some extent this reflects the synchronising impact of the Asian crisis and the 2000-2001 ICT bubble burst. However, even after the crisis and the ICT shock, synchronisation remained relatively high, largely as a result of higher correlation of output growth among the NICs. 
Allowing for more than one common factor, in order to identify possible subgroups of countries, we found that Taiwan and Singapore, and possibly Hong Kong, diverge somewhat from the general East Asian growth dynamics and a second factor can help to capture some of their idiosyncratic dynamics. Compared with growth synchronisation within the euro area, the synchronisation in East Asia over the entire sample appears to be somewhat higher. As suggested by a sub-sample analysis for the NICs, this appears to be, however, largely the result of the synchronising effect of the Asian crisis as the degree of synchronisation before the crisis is somewhat lower than that one of the euro area.

Regarding the possible factors underlying East Asian growth synchronisation, the factor analysis of different GDP components shows that a considerable part of the co-movement in East Asian economies appears to be the result of co-movement in exports. In fact, even Japan and China exhibit a considerable degree of co-movement with the rest of Asia with respect to their exports. In contrast, in the case of Japan neither private consumption nor investment show any tendency to co-move with these demand components in the rest of Asia. While exports are in general important for explaining Asian growth developments, this importance appears to have been somewhat reduced during the Asian crisis, as consumption and investment (with a lag) moved to the centre-stage. In the more recent 2000/2001 recession exports again played a more important role, while consumption proved relatively resilient. The importance of exports is also confirmed by an analysis of the supply side GDP components which shows that manufacturing is the sector with the strongest evidence for a broad-based significant common factor.

The subsequent analysis focused on three important structural factors possibly underlying East Asian synchronisation: Cross-country spill-over effects within the region, common exogenous shocks and interregional linkages. As to cross-country spill-over effects, we can identify some lagged effects of developments in Taiwan and Korea on the other two NICs, Singapore and Hong Kong, which may explain some of the co-movement within the NICs. Regarding common shocks, the paper assesses the role of a number of potential common exogenous factors in explaining the synchronisation of Asian activity. The analysis suggests that exogenous factors may indeed provide an important explanation for this co-movement. In particular, oil and commodity price movements and changes in the USD/JPY exchange rate appear to be relevant in that respect. Activity developments outside the region, on the other hand, appear to be less important, with international financial conditions being of only marginal importance.

Using a model specification with three area factors - for Asia, Continental Europe and North America we find that the Asian region is only weakly affected by developments in the other two regions. However, the Asian region seems to exert some influence on European growth and to a lesser extent also on North American growth. To the extent that Asian producers are forward-looking and anticipate future growth developments in the other two regions correctly, the lagged effect of Asia on the other regions may in fact reflect a causal relationship in the other direction. In any case, the empirical methodology only identifies interactions between the common elements in the regions growth dynamics and individual countries may be affected much more strongly and in very idiosyncratic ways by developments outside the East Asian region. 
In summary, the considerable co-movement of activity within East Asia appears to be driven to a large extent by developments outside the region, rather than by strong inter-regional linkages. Thus, although East Asia is evolving into an ever closer economic area with strong trade - and to a lesser extent financial - linkages between the various members, the region continues to be strongly exposed to extra-regional developments, reflecting to a large extent similar exposure in terms of export activity.

Of course, some of the results are likely to have been influenced by the Asian crisis and the subsequent burst of the ICT bubble. To some extent, co-movement related to such extraordinary events is also an important dimension of synchronisation and thus should be taken into account in the analysis, as it highlights common vulnerabilities and exposures in the region. At the same time, it might also overstate the evidence for synchronisation, especially since co-movement is more generally found to be stronger in downturns. Ideally, one should try to model such exceptional events explicitly or separate the analysis between "normal" and "crisis" periods. Given data limitations, this is unfortunately not possible at the present time for a study of Asian synchronisation. Further work will certainly be needed in the future in order to better understand the nature of Asian integration and its impact. Some of this can only be done as additional "non-crisis" observations are added to the evidence, unless the common experience of turbulent times remains an important feature of the Asian region. 
Appendix: Regression results for Section 10 - Common factors and exogenous variables

Regression of common factors on the price of Brent crude oil (first difference)

(First row: estimated coefficients, second row: t-statistics)

\begin{tabular}{|c|c|c|c|c|c|c|c|c|c|c|}
\hline \multirow[t]{2}{*}{ OIL } & \multicolumn{9}{|c|}{ Lags } & \multirow[b]{2}{*}{$\operatorname{adj.~R2~}$} \\
\hline & 0 & 1 & 2 & 3 & 4 & 5 & 6 & 7 & 8 & \\
\hline Asia & $\begin{array}{l}4.39 \\
2.46\end{array}$ & & & & & & & $\begin{array}{l}-2.15 \\
2.39\end{array}$ & $\begin{array}{l}-2.36 \\
-294\end{array}$ & 0.33 \\
\hline NIC & & & & & & & & & $\begin{array}{l}-1.62 \\
-2.01\end{array}$ & 0.04 \\
\hline NIC_93 & $\begin{array}{l}2.38 \\
3.20\end{array}$ & & & & & & & $\begin{array}{l}-2.19 \\
-2.95\end{array}$ & $\begin{array}{l}-2.97 \\
-5.55\end{array}$ & 0.41 \\
\hline ASEAN & $\begin{array}{l}3.90 \\
2.00\end{array}$ & & & & & & & & $\begin{array}{l}-1.99 \\
-2.51\end{array}$ & 0.19 \\
\hline
\end{tabular}

Regression of common factors on the HWWA commodity price index (first difference)

(First row: estimated coefficients, second row: t-statistics)

\begin{tabular}{|c|c|c|c|c|c|c|c|c|c|c|}
\hline \multirow[t]{2}{*}{ HWWA } & \multicolumn{9}{|c|}{ Lags } & \multirow[b]{2}{*}{$\operatorname{adj} . R 2$} \\
\hline & 0 & 1 & 2 & 3 & 4 & 5 & 6 & 7 & 8 & \\
\hline Asia & $\begin{array}{c}11.25 \\
2.16\end{array}$ & & & & & & & & & 0.17 \\
\hline NIC & $\begin{array}{l}4.64 \\
1.90 \\
\end{array}$ & & & & & & & & & 0.05 \\
\hline NIC_93 & $\begin{array}{l}6.19 \\
2.28 \\
\end{array}$ & & & $\begin{array}{r}-4.10 \\
-2.00 \\
\end{array}$ & & & & & & 0.11 \\
\hline ASEAN & $\begin{array}{c}10.39 \\
2.07\end{array}$ & & & & & & & & & 0.15 \\
\hline
\end{tabular}

Regression of common factors on the MSCI equity price index (first difference)

(First row: estimated coefficients, second row: t-statistics)

\begin{tabular}{|c|c|c|c|c|c|c|c|c|c|c|}
\hline \multirow[t]{2}{*}{$\mathrm{MSCl}$} & \multicolumn{9}{|c|}{ Lags } & \multirow[b]{2}{*}{$\operatorname{adj} . \mathrm{R} 2$} \\
\hline & 0 & 1 & 2 & 3 & 4 & 5 & 6 & 7 & 8 & \\
\hline Asia & & $\begin{array}{l}3.60 \\
1.91\end{array}$ & & & & & & & & 0.05 \\
\hline NIC & $\begin{array}{r}0.00 \\
-2.89\end{array}$ & $\begin{array}{l}4.27 \\
4.14\end{array}$ & $\begin{array}{l}3.75 \\
3.72\end{array}$ & & & & & & & $\overline{0.22}$ \\
\hline NIC_93 & & $\begin{array}{l}5.08 \\
3.07\end{array}$ & & & & & & & & 0.19 \\
\hline ASEAN & & & & & & & & & & $\overline{\mathrm{NA}}$ \\
\hline
\end{tabular}




\section{Regression of common factors on the US Federal Funds rate (level)}

(First row: estimated coefficients, second row: t-statistics)

\begin{tabular}{|l|c|c|c|c|c|c|c|c|c|c|}
\hline \multirow{2}{*}{ Fed Funds } & \multicolumn{9}{|c|}{ Lags } & \multirow{2}{*}{ adj. R2 } \\
\cline { 2 - 11 } & 0 & 1 & 2 & 3 & 4 & 5 & 6 & 7 & 8 & \\
\hline Asia & 0.75 & -0.77 & & & & & & & & 0.06 \\
& 3.75 & -3.95 & & & & & & & & \\
\hline NIC & 0.14 & & & -0.29 & & & 0.15 & & & 0.11 \\
& 2.61 & & & -3.11 & & & 0.06 & & & \\
\hline NIC_93 & 0.56 & & -0.81 & & & & 0.90 & -0.66 & & 0.15 \\
& 4.46 & & -3.85 & & & & 2.88 & -2.29 & & \\
\hline ASEAN & 0.66 & -0.69 & & & & & & & & 0.04 \\
& 2.99 & -3.07 & & & & & & & & \\
\hline
\end{tabular}

\section{Regression of common factors on the yield on 10-year US Treasuries (level)}

(First row: estimated coefficients, second row: t-statistics)

\begin{tabular}{|c|c|c|c|c|c|c|c|c|c|c|}
\hline \multirow[t]{2}{*}{ 10-year IR } & \multicolumn{9}{|c|}{ Lags } & \multirow[b]{2}{*}{$\operatorname{adj.R2}$} \\
\hline & 0 & 1 & 2 & 3 & 4 & 5 & 6 & 7 & 8 & \\
\hline Asia & $\begin{array}{l}0.70 \\
2.41\end{array}$ & & & $\begin{array}{l}-0.68 \\
-2.11\end{array}$ & & & & & & 0.18 \\
\hline NIC & $\begin{array}{l}0.40 \\
2.06\end{array}$ & $\begin{array}{l}-0.39 \\
-1.98\end{array}$ & & & & & & & & 0.04 \\
\hline NIC_93 & $\begin{array}{l}0.48 \\
2.41\end{array}$ & $\begin{array}{l}-0.48 \\
-2.24\end{array}$ & & & & & & & & 0.16 \\
\hline ASEAN & & & & & & & & & & NA \\
\hline
\end{tabular}

\section{Regression of common factors on the aggregate G7 GDP (first difference)}

(First row: estimated coefficients, second row: t-statistics)

\begin{tabular}{|c|c|c|c|c|c|c|c|c|c|c|}
\hline \multirow[t]{2}{*}{ D_G7_GDP } & \multicolumn{9}{|c|}{ Lags } & \multirow[b]{2}{*}{$\operatorname{adj.~R2~}$} \\
\hline & 0 & 1 & 2 & 3 & 4 & 5 & 6 & 7 & 8 & \\
\hline Asia & $\begin{array}{c}114.79 \\
5.52\end{array}$ & & & & $\begin{array}{c}-116.29 \\
-2.19\end{array}$ & & & & & 0.14 \\
\hline $\mathrm{NIC}$ & $\begin{array}{l}62.15 \\
2.50\end{array}$ & $\begin{array}{c}50.64 \\
4.04 \\
\end{array}$ & & & & & & & & 0.17 \\
\hline NIC_93 & $\begin{array}{c}111.59 \\
4.97\end{array}$ & & & & $\begin{array}{c}-107.10 \\
-3.97\end{array}$ & & & & & 0.25 \\
\hline ASEAN & & & & & & & & & & NA \\
\hline
\end{tabular}

\section{Regression of common factors on the nominal USD-JPY exchange rate (first difference)}

(First row: estimated coefficients, second row: t-statistics)

\begin{tabular}{|l|c|c|c|c|c|c|c|c|c|c|}
\hline \multirow{2}{*}{ D-USDJPY } & \multicolumn{9}{|c|}{ Lags } & \multirow{2}{*}{ adj. R2 } \\
\cline { 2 - 11 } & 0 & 1 & 2 & 3 & 4 & 5 & 6 & 7 & 8 & \\
\hline Asia & -6.24 & & & & & & & & & 0.07 \\
& -2.09 & & & & & & & & & \\
\hline NIC & -3.09 & -3.54 & -5.78 & & -3.25 & & & & & 0.22 \\
& -2.26 & -2.71 & -4.65 & & -2.39 & & & & & \\
\hline NIC_93 & & & -4.77 & & & & & & & 0.07 \\
& & & -1.92 & & & & & & & \\
\hline ASEAN & -6.53 & & & & & & & & & 0.07 \\
& -1.97 & & & & & & & & & \\
\hline
\end{tabular}




\section{Bibliography}

Abeysinghe, Tilak and Kristin Forbes. 2005. "Trade linkages and output-multiplier effects: A structural VAR approach with a focus on Asia”, Review of International Economics, 13, 2, pp. 356-375.

Backus, David, K., Patrick J. Kehoe and Finn E. Kydland. 1992. "International real business cycles”, Journal of Political Economy, 100, 4, pp. 745-775.

Bayoumi, Tamim and Barry Eichengreen. 1994. "One money or many? Analyzing the prospects for monetary unification in various parts of the world”, Princeton Studies in International Finance, No. 76.

Bayoumi, Tamim and Paolo Mauro. 2001. "The suitability of ASEAN for a regional currency arrangement”, The World Economy, 24, 7, pp. 933-954.

Baxter, Marianne and Alan C. Stockman. 1989. "Business cycles and the exchange rate regime: some international evidence”, Journal of Monetary Economics, 23, 3, pp. 377-400.

Bayoumi, Tamim, Barry Eichengreen and Paolo Mauro. 2000. "On regional monetary arrangements for ASEAN”, Journal of the Japanese and International Economies, 14, 12, pp. 121-148.

Bordo, Michale D. and Thomas Helbling. 2003. "Have national business cycles become more synchronized?”, NBER Working Paper No. 10130.

Canova, Fabio and Harris Dellas. 1993. "Trade interdependence and the international business cycle”, Journal of International Economics, 34, pp. 23-47.

Cerra, Velerie and Sweta C. Saxena. 2003. “Did output recover from the Asian crisis?”, IMF Working Paper No. 03/48.

Clark, Todd E. and Eric von Wincoop. 2001. "Borders and business cycles”, Journal of International Economics, 55, 1, pp. 59-85.

Coe, David T. and Elhanan Helpman. 1995. "International R\&D spillovers”, European Economic Review, 39, 5, pp. 859-887.

Crosby, Mark. 2003. “Business cycle correlations in Asia-Pacific”, Economics Letters, 80, 1, pp. 35-44.

Engle, Robert F. and Mark Watson. 1981. "A one-factor multivariate time series model of metropolitan wage rates”, Journal of the American Statistical Association, 76, 376, pp. 774-781.

Forni, Mario and Lucrezia Reichlin. 1998. "Let’s get real: A dynamic factor analytical approach to disaggregated business cycle”, Review of Economic Studies, 65, 3, pp. 453-474.

Frankel, Jeffrey and Andrew Rose. 1998. "The endogeneity of the optimum currency area criteria”, The Economic Journal, 108, 449, pp. 1009-1025.

Garcia Herrero, Alicia and Juan M. Ruiz. 2005. "How much do trade and financial linkages affect business cycle synchronization for small open economies?”, manuscript, Bank of Spain. 
Girardin, Eric. 2002. "Does Japan share a common business cycle with other east Asian countries?”, Unpublished manuscript, Université de la Méditerranée.

Gregory, Allan W., Allen C. Head and Jacques Raynauld. 1997. "Measuring world business cycles”, International Economic Review, 38, 3, pp. 677-701.

Harding, Don and Adrian Pagan. 2002. "Synchronization of cycles”, The Australian National University, CAMA Working Paper 3/2004.

Imbs, Jean. 2004. “Trade, finance, specialization, and synchronization”, The Review of Economics and Statistics, 86, 3, pp. 723-734.

Isogai Takashi and Shunichi Shibanuma. 2000. “East Asia's Intra- and Inter-Regional Economic Relations; Data Analyses on Trade, Direct Investments and Currency Transactions”, Bank of Japan Working Paper Series 00-E-4.

Isogai Takashi, Hirofumi Morishita and Rasmus Rüffer. 2002. “Analysis of Intra- and Interregional Trade in East Asia: Comparative Advantage Structure and Dynamic Interdependence in Trade Flows”, Bank of Japan International Department Discussion Paper 02-E-1.

Kalemli-Ozcan, Sebnem, Bent E. Sorensen and Oved Yosha. 2001. "Economic integration, industrial specialization, and the asymmetry of macroeconomic fluctuations”, Journal of International Economics, 55, 1, pp. 107-137.

Kapetanios, George and Massimiliano Marcellino. 2003. “A comparison of estimation methods for dynamic factor models of large dimensions”, Queen Mary University of London Working Paper No. 489.

Kose, Ayhan M., Christopher Otrok and Charles H. Whiteman. 2003. "International business cycles: World, region, and country-specific factors”, American Economic Review, 93, 4, pp. 12161239.

Kose, Ayhan M. and Kei-Mu Yi. 2002. "The trade-comovement problem in international macroeconomics”, Federal Reserve Bank of New York Staff Report No. 155.

Krugman, Paul. 1993. "Lessons of Massachusetts for EMU”, in F. Giavazzi and F. Torres (eds.): The Transition to Economic and Monetary Union in Europe, Cambridge University Press, New York, pp. 241-261.

Lippi, Marco and Daniel L. Thornton. 2004. "A dynamic factor analysis of the response of U.S. interest rates to news”, Federal Reserve Bank of St. Louis Working Paper No. 2004-013A.

Loayza, Norman, Humberto Lopez and Angel Ubide. 2001. "Comovements and sectoral interdependence: Evidence for Latin America, East Asia, and Europe”, IMF Staff Papers, 48, 2, pp. 367-396.

Lumsdaine, Robin L. and Eswar Prasad. 1997. "Identifying the common component in international fluctuations”, NBER Working Paper No. 5984.

Malek Mansour, Joffrey. 2003. “Do national business cycles have an international origin?”, Empirical Economics, 28, 2, pp. 223-247. 
McKinnon, Ronald. and Gunther Schnabl. 2003. "Synchronized business cycles in East Asia and fluctuations in the Yen/Dollar exchange rate”, The World Economy, 26, 8, pp. 1067-1088.

Monfort, Alain, Jean-Paul Renne, Rasmus Rüffer and Giovanni Vitale. 2003. "Is economic activity in the G7 synchronised? Common shocks versus spillover effects”, CEPR Discussion Paper No. 4119.

Mundell, R. 1961. “A Theory of Optimum Currency Area”, American Economic Review, 60, pp. 657665.

Norrbin, Stefan C. and Don E. Schlagenhauf. 1996. "The role of international factors in the business cycle”, Journal of International Economics, 40, 1-2, pp. 85-104.

Selover, David D. 1999. "International interdependence and business cycle transmission in ASEAN”, Journal of the Japanese and International Economies, 13, pp. 230-253.

Selover, David D. 2004. "International co-movements and business cycle transmission between Korea and Japan”, Journal of the Japanese and International Economies, 18, 1, pp. 57-83.

Shin, Kwanho and Yunjong Wang. 2003. "Trade integration and business cycle synchronization in East Asia”, Asian Economic Papers, 2, pp. 1-20.

Shin, Kwanho and Yunjong Wang. 2004. "Trade integration and business cycle co-movements: The case of Korea with other Asian countries”, Japan and the World Economy, 16, 2, pp. 213-230.

Stock, James H. and Mark W. Watson. 1991. “A probability model of coincident economic indicators”, in K. Lahiri and G.H. Moore, eds., Leading Economic Indicators: New Approaches and Forecasting Records, Cambridge University Press, Cambridge, pp. 63-89.

Stock, James H. and Mark W. Watson. 1998. “Diffusion indexes”, NBER Working Paper No. 6702.

Stock, James H. and Mark W. Watson. 2001. "Macroeconomic forecasting using diffusion indexes”, Journal of Business and Economic Statistics, 20, pp. 147-162.

Yu, Tzong-Shian. 2003. “Can East Asia rise again?”, Journal of Asian Economics, 13, 6, pp. 715-729. 


\section{European Central Bank Working Paper Series}

For a complete list of Working Papers published by the ECB, please visit the ECB's website (http://www.ecb.int)

617 "New survey evidence on the pricing behaviour of Luxembourg firms" by P. Lünnemann and T. Y. Mathä, May 2006.

618 "The patterns and determinants of price setting in the Belgian industry" by D. Cornille and M. Dossche, May 2006.

619 "Cyclical inflation divergence and different labor market institutions in the EMU" by A. Campolmi and E. Faia, May 2006.

620 "Does fiscal policy matter for the trade account? A panel cointegration study" by K. Funke and C. Nickel, May 2006.

621 "Assessing predetermined expectations in the standard sticky-price model: a Bayesian approach" by P. Welz, May 2006.

622 "Short-term forecasts of euro area real GDP growth: an assessment of real-time performance based on vintage data" by M. Diron, May 2006.

623 "Human capital, the structure of production, and growth" by A. Ciccone and E. Papaioannou, May 2006.

624 "Foreign reserves management subject to a policy objective" by J. Coche, M. Koivu, K. Nyholm and V. Poikonen, May 2006.

625 "Sectoral explanations of employment in Europe: the role of services" by A. D'Agostino, R. Serafini and M. Ward-Warmedinger, May 2006.

626 "Financial integration, international portfolio choice and the European Monetary Union" by R. A. De Santis and B. Gérard, May 2006.

627 "Euro area banking sector integration: using hierarchical cluster analysis techniques" by C. Kok Sørensen, J. M. Puigvert Gutiérrez, May 2006.

628 "Long-run money demand in the new EU Member States with exchange rate effects" by C. Dreger, H.-E. Reimers and B. Roffia, May 2006.

629 “A market microstructure analysis of foreign exchange intervention” by P. Vitale, May 2006.

630 “Implications of monetary union for catching-up member states” by M. Sánchez, May 2006.

631 "Which news moves the euro area bond market?" by M. Andersson, L. J. Hansen and S. Sebestyén, May 2006.

632 "Does information help recovering structural shocks from past observations?" by D. Giannone and L. Reichlin, May 2006.

633 "Nowcasting GDP and inflation: the real-time informational content of macroeconomic data releases” by D. Giannone, L. Reichlin and D. H. Small, May 2006.

634 "Expenditure reform in industrialised countries: a case study approach" by S. Hauptmeier, M. Heipertz and L. Schuknecht, May 2006. 
635 "Identifying the role of labor markets for monetary policy in an estimated DSGE model" by K. Christoffel, K. Kuester and T. Linzert, June 2006.

636 "Exchange rate stabilization in developed and underdeveloped capital markets" by V. Chmelarova and G. Schnabl, June 2006.

637 "Transparency, expectations, and forecasts" by A. Bauer, R. Eisenbeis, D. Waggoner and T. Zha, June 2006.

638 "Detecting and predicting forecast breakdowns" by R. Giacomini and B. Rossi, June 2006.

639 "Optimal monetary policy with uncertainty about financial frictions" by R. Moessner, June 2006.

640 “Employment stickiness in small manufacturing firms” by P. Vermeulen, June 2006.

64I "A factor risk model with reference returns for the US dollar and Japanese yen bond markets" by C. Bernadell, J. Coche and K. Nyholm, June 2006.

642 "Financing constraints and firms' cash policy in the euro area" by R. Pál and A. Ferrando, June 2006.

643 "Inflation forecast-based-rules and indeterminacy: a puzzle and a resolution" by P. Levine, P. McAdam and J. Pearlman, June 2006.

644 "Adaptive learning, persistence, and optimal monetary policy" by V. Gaspar, F. Smets and D. Vestin, June 2006.

645 “Are internet prices sticky?” by P. Lünnemann and L. Wintr, June 2006.

646 "The Dutch block of the ESCB multi-country model” by E. Angelini, F. Boissay and M. Ciccarelli, June 2006.

647 "The economic effects of exogenous fiscal shocks in Spain: a SVAR approach" by F. de Castro Fernández and P. Hernández de Cos, June 2006.

648 "Firm-specific production factors in a DSGE model with Taylor price setting" by G. de Walque, F. Smets and R. Wouters, June 2006.

649 "Monetary and fiscal policy interactions in a New Keynesian model with capital accumulation and non-Ricardian consumers" by C. Leith and L. von Thadden, June 2006.

650 "A structural break in the effects of Japanese foreign exchange intervention on yen/dollar exchange rate volatility" by E. Hillebrand and G. Schnabl, June 2006.

651 "On the determinants of external imbalances and net international portfolio flows: a global perspective" by R. A. De Santis and M. Lührmann, July 2006.

652 "Consumer price adjustment under the microscope: Germany in a period of low inflation" by J. Hoffmann and J.-R. Kurz-Kim, July 2006.

653 "Acquisition versus greenfield: the impact of the mode of foreign bank entry on information and bank lending rates" by S. Claeys and C. Hainz, July 2006.

654 "The German block of the ESCB multi-country model" by I. Vetlov and T. Warmedinger, July 2006.

655 "Fiscal and monetary policy in the enlarged European Union" by S. Pogorelec, July 2006. 
656 "Public debt and long-term interest rates: the case of Germany, Italy and the USA" by P. Paesani, R. Strauch and M. Kremer, July 2006.

657 "The impact of ECB monetary policy decisions and communication on the yield curve" by C. Brand, D. Buncic and J. Turunen, July 2006.

658 "The response of firms' investment and financing to adverse cash flow shocks: the role of bank relationships" by C. Fuss and P. Vermeulen, July 2006.

659 "Monetary policy rules in the pre-EMU era: Is there a common rule?" by M. Eleftheriou, D. Gerdesmeier and B. Roffia, July 2006.

660 "The Italian block of the ESCB multi-country model” by E. Angelini, A. D'Agostino and P. McAdam, July 2006.

661 "Fiscal policy in a monetary economy with capital and finite lifetime" by B. Annicchiarico, N. Giammarioli and A. Piergallini, July 2006.

662 "Cross-border bank contagion in Europe" by R. Gropp, M. Lo Duca and J. Vesala, July 2006.

663 "Monetary conservatism and fiscal policy” by K. Adam and R. M. Billi, July 2006.

664 “Fiscal convergence before entering the EMU” by L. Onorante, July 2006.

665 "The euro as invoicing currency in international trade" by A. Kamps, August 2006.

666 "Quantifying the impact of structural reforms" by E. Ernst, G. Gong, W. Semmler and L. Bukeviciute, August 2006.

667 "The behaviour of the real exchange rate: evidence from regression quantiles" by K. Nikolaou, August 2006.

668 "Declining valuations and equilibrium bidding in central bank refinancing operations" by C. Ewerhart, N. Cassola and N. Valla, August 2006.

669 "Regular adjustment: theory and evidence” by J. D. Konieczny and F. Rumler, August 2006.

670 "The importance of being mature: the effect of demographic maturation on global per-capita GDP” by R. Gómez and P. Hernández de Cos, August 2006.

67I "Business cycle synchronisation in East Asia” by F. Moneta and R. Rüffer, August 2006. 
